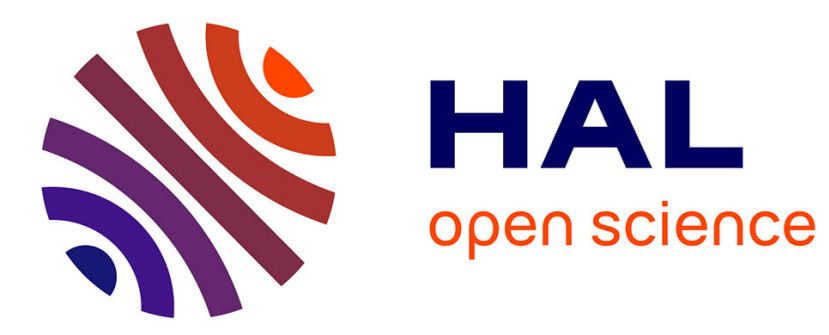

\title{
SUPPLY CHAIN DESIGN AND COST ANALYSIS THROUGH SIMULATION
}

\author{
Eleonora Bottani, Roberto Montanari
}

\section{To cite this version:}

Eleonora Bottani, Roberto Montanari. SUPPLY CHAIN DESIGN AND COST ANALYSIS THROUGH SIMULATION. International Journal of Production Research, 2010, 48 (10), pp.28592886. 10.1080/00207540902960299 . hal-00580110

\section{HAL Id: hal-00580110 https://hal.science/hal-00580110}

Submitted on 26 Mar 2011

HAL is a multi-disciplinary open access archive for the deposit and dissemination of scientific research documents, whether they are published or not. The documents may come from teaching and research institutions in France or abroad, or from public or private research centers.
L'archive ouverte pluridisciplinaire HAL, est destinée au dépôt et à la diffusion de documents scientifiques de niveau recherche, publiés ou non, émanant des établissements d'enseignement et de recherche français ou étrangers, des laboratoires publics ou privés. 


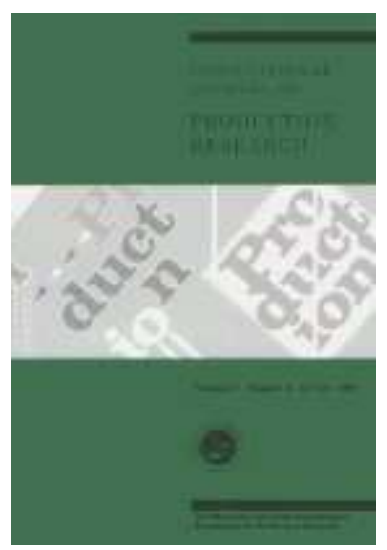

\section{SUPPLY CHAIN DESIGN AND COST ANALYSIS THROUGH SIMULATION}

\begin{tabular}{|c|c|}
\hline Journal: & International Journal of Production Research \\
\hline Manuscript ID: & TPRS-2008-IJPR-0439.R2 \\
\hline Manuscript Type: & Original Manuscript \\
\hline $\begin{array}{r}\text { Date Submitted by the } \\
\text { Author: }\end{array}$ & 02-Apr-2009 \\
\hline Complete List of Authors: & $\begin{array}{l}\text { Bottani, Eleonora; University of Parma, Industrial Engineering } \\
\text { Montanari, Roberto; University of Parma, Department of Industrial } \\
\text { Engineering }\end{array}$ \\
\hline Keywords: & $\begin{array}{l}\text { SUPPLY CHAIN MANAGEMENT, SIMULATION, COST ANALYSIS, } \\
\text { BULLWIP EFFECT, DESIGN OF EXPERIMENTS }\end{array}$ \\
\hline Keywords (user): & SUPPLY CHAIN MANAGEMENT, SIMULATION \\
\hline
\end{tabular}

\section{S ScholaroNE \\ Manuscript Central}




\title{
SUPPLY CHAIN DESIGN AND COST ANALYSIS
}

\section{THROUGH SIMULATION}

\author{
Eleonora BOTTANI, Roberto MONTANARI \\ Department of Industrial Engineering - University of Parma \\ viale G.P.Usberti 181/A, 43100 Parma (ITALY)
}

Please address correspondence to

Eleonora BOTTANI, Eng. Ph.D.

Lecturer - Logistics and Supply Chain Management

phone +390521 905872; fax +390521905705

eleonora.bottani@unipr.it 


\title{
SUPPLY CHAIN DESIGN AND COST ANALYSIS THROUGH SIMULATION
}

\begin{abstract}
This paper is grounded on a discrete-event simulation model, reproducing a Fast Moving Consumer Goods (FMCG) supply chain, and aims at quantitatively assessing the effects of different supply configurations on the resulting total supply chain costs and bullwhip effect. Specifically, 30 supply chain configurations are examined, stemming from the combination of several supply chain design parameters, namely number of echelons (from 3 to 5), reorder and inventory management policies (EOQ vs EOI), demand information sharing (absence $v s$ presence of information sharing mechanisms), demand value (absence vs presence of demand "peak"), responsiveness of supply chain players. For each configuration, the total logistics costs and the resulting demand variance amplification are computed. A subsequent statistical analysis is performed on 20 representative supply chain configurations, with the aim to identify significant single and combined effects of the above parameters on the results observed.
\end{abstract}

From effects analysis, bullwhip effect and costs outcomes, 11 key results are derived, which provide useful insights and suggestions to optimize supply chain design.

Keywords: supply chain management, supply chain design, simulation model, economical analysis, design of experiments, Fast Moving Consumer Goods.

\section{Introduction}

The concept of Supply Chain Management (SCM) is gaining increased importance in today's economy, due to its impact on firms' competitive advantage. SCM describes the discipline of optimizing the delivery of goods, services and related information from supplier to customer, and is concerned with the effectiveness of dealing with final customer demand by the parties engaged in the provision of the product as a whole (Cooper et al., 1997). 
Efficiently and effectively managing the flow of material from supply sources to the ultimate customer involves proper design, planning and control of supply chains, and offers opportunities in terms of quality improvement, cost and lead time reduction (Persson \& Olhager, 2002), rapid response to changes or new developments (Bowersox \& Closs, 1996). According to Lambert, (2001), managing the supply chain involves three interrelated topics, namely (i) defining the supply chain (or supply network) structure, (ii) identifying the supply chain business processes and (iii) identifying the business components. The first topic, in particular, encompasses a set of decisions concerning, among others, number of echelons required and number of facilities per echelon, reorder policy to be adopted by echelons, assignment of each market region to one or more locations, and selection of suppliers for subassemblies, components and materials (Chopra \& Meindl, 2004; Hammami et al., 2008). Moreover, different supply chain configurations react differently to the bullwhip effect, a wellknown wasteful phenomenon involved by lack of information sharing across the supply chain. Hence, they result in different levels of safety stocks required (Lee et al., 2004).

This paper examines the effects of different configurations on the supply chain costs and bullwhip effect, with the ultimate aim to provide insights to optimize supply chain design. We consider the following design parameters: number of echelons, reorder policy, information sharing mechanisms, demand value, and responsiveness of supply chain players (see Lowson, et al., 1999, for a formal definition of responsiveness). The analysis is based on a discrete-event simulation model, reproducing a Fast Moving Consumer Goods (FMCG) supply chain, and on the computation of total logistics costs and of the demand variance amplification for the supply chain configurations examined. A subsequent statistical analysis is performed to identify and quantify single and combined effects of the above parameters on the results observed.

The paper is organized as follows. The next section reviews the relevant literature concerning supply chain simulation studies, with a particular attention to works focusing on supply chain design and optimization. In section 3, we describe the simulation model developed to reproduce 
the FMCG supply chain (some details concerning the FMCG examined and the corresponding data are proposed in Appendix). The key results of the simulation runs and effects analysis are detailed in section 4. Concluding remarks and future research directions are finally proposed.

\section{Literature analysis: supply chain simulation}

Simulation represents one of the tools most frequently used to observe the behaviour of supply chains, in order to highlight their efficiency level and evaluate new management solutions in a relatively short time (Iannone et al., 2007). A main advantage of simulation models can be found in their capability to provide estimates of efficiency and effectiveness of systems and to assess the impact of changed input parameters on the resulting performance, without examining real case examples (Harrison et al., 2007).

In the context of supply chain analysis, Persson \& Olhager, (2002), develop a simulation model to examine a case study company. They evaluate alternative supply chain scenarios, with the aim to improve the resulting quality and costs; moreover, the authors strive to understand how quality and costs affect each other. Sen et al., (2004), exploit simulation to examine viable supply chain positioning strategy, such as make-to-stock, make-to-order, and assemble-to-order, and explore possible integrations between those strategies, referring to a company in the electronic industry. Similarly, a simulation model is developed by Higuchi \& Troutt, (2004), to investigate the bullwhip effect and boom-and-bust phenomena, in the particular context of short life cycle products. Chan \& Chan, (2005), use simulation for building and testing five different supply chain models. Their main aim is to determine which supply chain models could achieve the optimal performance, in term of inventory level, order lead time, resources utilization, and transportation costs. Persson \& Araldi, (2007), developed a supply chain design tool integrating the Supply Chain Operation Reference (SCOR) methodology with discrete event simulation. The model is particularly suitable to be used when attempting to study the supply chain from a dynamic perspective, by analyzing the effect of changes in supply chain structure on the 
resulting performance. Longo \& Mirabelli, (2008), develop an advanced simulation model to support supply chain management. Their research focuses on two main objectives, namely developing a flexible and efficient simulator and implementing a decision making tool for supply chain managers. Several simulation studies have also been developed with the aim to assess the impact of information sharing mechanisms on the resulting supply chain costs and performance (e.g. Zhang \& Zhang, 2007; Lau et al., 2005; Zhao \& Xie, 2002).

However, the existing literature is often limited to the analysis of few supply chain configurations, usually referring to a two-echelon system, or specific SCM topics (e.g. information sharing, reorder policy or manufacturing strategy). Consequently, the issue of optimizing the supply chain configuration is not fully embraced in those works. A limited number of works either deal with more complex supply chains or examine multiple configurations. Among these, Hwarng et al., (2005), modelled a complex supply chain and investigate the effects of several parameters, including demand and lead time distribution, and postponement strategies, on the resulting performance. Similarly, Shang et al., (2004), applied simulation, Taguchi method and response surface methodology to identify the 'best' operating conditions for a supply chain. They examined the following supply chain parameters: information sharing, postponement, capacity, reorder policy, lead time and supplier's reliability. In this work, we exploit simulation with the aim to analyze a complex supply chain, encompassing up to 5 echelons, and apply experimental design to examine different operational conditions of the supply chain, resulting from the combination of several input parameters. As the supply chain network continues to grow in complexity, both in terms of number of levels and number of linkages, examining complex scenarios is required to derive insights for supply chain optimization. Simulations are also completed by a detailed economical analysis of the scenarios examined. 


\section{The simulation model}

\subsection{General overview}

The simulation model has been developed under Simul ${ }^{\mathrm{TM}}$ Professional, release 12 (Visual Thinking International Inc.). The nomenclature proposed in TABLE 1 is used to describe the model and the corresponding input parameters.

\section{INSERT TABLE 1}

In this study, we adopt the representation by Shapiro (2001), suggesting that the supply chain can be described in terms of two main processes, namely products flow and orders flow. Accordingly, the generic $i$-th echelon $(i=1, . . N)$ receives orders from echelon $i$ - 1 and products (i.e. pallets) from echelon $i+1$, through transport activities. For each echelon, a procurement lead time $L_{i}$ is introduced, encompassing the time required for transports, ordering and warehousing activities. We assume deterministic lead time (Dejonckheere et al., 2003), and thus order crossover phenomena (Reizebos, 2006) are not considered in this study. For simplicity, we model the flow of a single product.

According to several studies in literature (Chatfield et al., 2004; Zhang, 2004), the number of players per echelon is set at one. Echelon 1 (i.e., the retail store) directly faces the final customer's demand, whose value at day $t$ is $d_{t}$. Customer's demand is a stochastic variable, with normal distribution $N(\mu ; \sigma)$. Other supply chain players (except the manufacturer) forecast demand through a moving average model based on the last $m$ observations (Chen et al., 2000; Zhang, 2004; Sun \& Ren, 2005).

Each player stores product in a warehouse, whose inventory level is initially set at a defined value. This latter is assumed to be the same for all echelons considered, except echelon $N$, for which an infinite stock availability is hypothesised. 


\subsection{The supply chain configurations considered}

In this section, we describe the supply chain configurations examined in this study, in terms of the following parameters: (i) number of players; (ii) reorder policy; (iii) demand information sharing mechanisms; and (iv) demand behaviour.

\subsubsection{Number of echelons}

The supply chain modelled may range from 3 (i.e. manufacturer - distributor - retail store) up to 5 echelons (i.e. manufacturer - distributor 1 - distributor 2 - distributor3 - retail store).

\subsubsection{Reorder policy}

Each player can place orders according to an Economic Order Quantity (EOQ) or Economic Order Interval (EOI) policy. The same reorder policy is assumed for all supply chain players. Under EOI policy, the reorder process of echelon $i$ can be described as follows:

i. at time $t\left(t=1, \ldots N_{\text {days }}\right)$, the $i$-th echelon estimates demand mean $\left(\mu_{t, i}\right)$ and standard deviation $\left(\sigma_{t, i}\right)$ according to the moving average model, i.e.:

$$
\begin{aligned}
& \mu_{t, i}=\frac{1}{m} \sum_{k=t-m}^{t} d_{k, i} \\
& \sigma_{t, i}^{2}=\frac{1}{m-1} \sum_{k=t-m}^{t}\left(d_{k, i}-\mu_{t, i}\right)^{2}
\end{aligned}
$$

where $d_{t, i}$ indicates the demand faced by echelon $i$ at time $t$, corresponding either to the final customer's demand or to orders placed by echelon $i$ - 1 , i.e.:

$$
d_{t, i}=\left\{\begin{array}{cc}
d_{t} & i=1 \\
O_{t, i-1} & i=2, \ldots N-1
\end{array}\right.
$$

ii. the above values are used to compute the order-up-to level at time $t\left(O U L_{t, i}\right)$, according to eq.3 (Bottani et al., 2007; Dejonckheere et al., 2003):

$$
O U L_{t, i}=\left(\Delta t+L_{i}\right) \mu_{t, i}+k \sqrt{\left(\Delta t+L_{i}\right) \sigma_{t, i}^{2}}
$$


iii. each $\Delta t$, the supply chain player checks the stock available $I_{t-1, i}$ to decide whether to place an order. The amount of product to be ordered is derived as $O U L_{t, i}-I_{t-1, i}$. It should be noted that $I_{t-1, i}$ also takes into account products ordered but not yet received;

iv. whenever the order is placed, the inventory level $I_{t, i}$ is updated based on $O U L_{t, i}$.

Under EOQ policy, the reorder process of echelon $i$ is as follows:

i. $\quad$ eq. 1 is exploited to estimate $\mu_{t, i}$ and $\sigma_{t, i}$ at time $t$;

ii. the above parameters are used to compute the value of $O P_{t, i}$, based on eq.4 (Bottani et al., 2007; Dejonckheere et al., 2003):

$$
O P_{t, i}=L_{i} \mu_{t, i}+k \sqrt{L_{i} \sigma_{t, i}^{2}}
$$

iii. in the case $I_{t-1, i}<O P_{t, i}$, the supply chain player places an order. The quantity to be ordered $Q_{t, i}$ is computed starting from $\mu_{t, i}$, as detailed below:

$$
Q_{t, i}=\sqrt{\frac{2 \times \mu_{t, i} \times c_{o}}{h}}
$$

iv. at time $t$, the inventory level $I_{t, i}$ of echelon $i$ is updated based on the observed demand $d_{t, i}$, i.e.

$$
I_{t, i}=I_{t-1, i}-d_{t, i}+Q_{t, i}
$$

As we modelled a stochastic demand, orders placed by supply chain players could always exceed the available product stock, resulting in a stock-out. Under such circumstance, orders are fulfilled by an external supplier, with infinite products availability. The overall quantity supplied by this player $\left(Q_{\text {stock-out }}\right)$ is used to assess the corresponding stock-out costs. In the case the stock-out occurs at the retail store, it is assumed that the final customer buys the quantity of products available; conversely, for all the remaining players, $Q_{\text {stock-out }, i}$ accounts for the whole quantity ordered to echelon $i$. Eq.7 summarises the computation of $Q_{\text {stock-out }, i}$ : 
Due to infinite stock availability, no stock-out may occur for the manufacturer.

\subsubsection{Information sharing mechanisms}

Point of sale (POS) data can be shared between supply chain players or only available to the retail store. Under this latter scenario, echelon $i$ forecasts demand only based on $d_{t, i}$ previously defined in eq.2. Conversely, when POS data are shared, this additional information is available to all supply chain players to forecast demand. Hence, for $i=1, \ldots N-1$ we have $d_{t, i}=d_{t}$ in eq.2.

FIGURE 1 and FIGURE 2 show a scheme of the model structure (in terms of products, orders and information flow) respectively under absence of information sharing and when information sharing mechanisms are implemented.

\section{INSERT FIGURE 1 AND FIGURE 2}

Demand information sharing can be seen as a possible consequence of the adoption of advanced Information Technology (IT) tools for product identification and monitoring. This is, for instance, the case of Radio Frequency Identification (RFID) coupled with EPC Network (Bottani \& Rizzi, 2008).

\subsubsection{Demand behaviour}

The final customer's demand may or may not experience an increase, referred to as demand "peak", during a simulation run. In the case of non-increase, the demand mean and standard deviation are known parameters $(\mu$ and $\sigma)$. When simulating an increase in demand, the demand mean and standard deviation are changed to $\mu^{\prime}=2 \mu$ and $\sigma^{\prime}=\sigma^{\sqrt{2}}$ at the middle of the simulation, and kept unchanged until the simulation ends.

Under the EOQ policy, the "peak" of demand involves updating $Q_{t, i}$ and $O P_{t, i}$ parameters, by exploiting eqs.4-5 with $\mu^{\prime}$ and $\sigma^{\prime}$. The same happens, under EOI policy, for the $O U L_{t, i}$ parameter 
(eq.3). Moreover, the reorder interval $\Delta t$ also depends on the demand mean; in this regard, in real cases, it is expected that each supply chain echelon will modify $\Delta t$ based on $\mu^{\prime}$ and $\sigma^{\prime}$. In modelling this behaviour, we consider two additional scenarios, namely:

a. "responsive" supply chain players (Lowson et al., 1999) $-\Delta t$ is updated 3 days after the demand "peak" occurred;

b. "non-responsive" supply chain players - $\Delta t$ is updated 5 days after the demand "peak" occurred.

\subsection{Experiments setting and outcomes}

To provide a detailed investigation of the supply chain, we examine 30 different scenarios, which are obtained by combining the parameters described in the above sections, according to Design of Experiments (DoE) (Montgomery \& Runger, 2003). The resulting scheme is proposed in FIGURE 3.

\section{INSERT FIGURE 3}

For each scenario, we assessed the outputs listed below (numerical values of input parameters required for the computation are detailed in section 3.4):

i. Bullwhip effect, defined as the ratio between variance of orders received by echelon $N$ and the variance of final customer's demand, i.e. $\frac{\sigma_{N}^{2}}{\sigma^{2}}$. Under "peak" of demand, the resulting $\sigma$ is analytically computed based on $d_{t}$ values;

ii. cost of holding stocks $\left(C_{\text {stocks }}\right)$ : it is computed starting from unitary cost of stocks and amount of stock available at the warehouse, i.e.:

$$
\left\{\begin{array}{l}
C_{\text {stocks }, i}=h \sum_{t=1}^{N_{\text {days }}} I_{t, i} \\
C_{\text {stocks }}=\sum_{i=1}^{N-1} C_{s t o c k s, i}
\end{array}\right.
$$


Due to infinite stock availability, such cost is not computed for the manufacturer;

iii. stock-out cost $\left(C_{\text {stock-out }}\right)$ : it is computed starting from the mark-up applied by each supply chain player $\left(c_{i}\right)$, corresponding to the economical loss experienced, and from $Q_{\text {stock-out, }, i}$, as described by eq.9:

$$
\left\{\begin{aligned}
C_{\text {stock-out }, i} & =C_{i} \sum_{t=1}^{N_{\text {days }}} Q_{\text {stock-out }, t_{t} i} \\
C_{\text {stock-out }} & =\sum_{i=1}^{N-1} C_{\text {stock-out }, i}
\end{aligned}\right.
$$

iv. order cost $\left(C_{\text {order }}\right)$ : it results from unitary cost of orders $c_{o}$ and number of orders placed by supply chain players $N_{\text {orders }, i}$ (except the manufacturer), i.e.:

$$
C_{\text {order }}=c_{o} \sum_{i=1}^{N-1} N_{\text {orders }, i}
$$

The number of orders is a direct outcome of the simulation run;

v. transport cost $\left(C_{\text {transport }}\right)$ : transport cost is assumed not to be affected by the order quantity, and to only depend upon the number of orders fulfilled. It thus results from $N_{\text {orders }, i}$ and unitary cost of transport $\left(c_{t}\right)$, according to eq.11:

$$
C_{\text {transport }}=C_{t} \sum_{i=1}^{N-1} N_{\text {orders }, i}
$$

vi. shipping/receiving cost $\left(C_{\text {shipping/receiving }}\right)$ : for each echelon, this cost is derived from average number of pallets handled per year, average hourly cost of manpower $\left(c_{m}\right)$ and time required to handle a pallet $\left(t_{\text {pallet }}\right)$. As the model considers a player per echelon, the average number of pallets handled reflects the average customer's demand $(\mu)$, which is the same for all echelons. Hence, $C_{\text {shipping/receiving }}$ only depends on the number of echelons considered. In the computation, it should also be considered that the manufacturer only performs shipping activities, while the retail store only performs receiving activities. The following formula is thus used to assess $C_{\text {shipping/receiving: }}$ 


$$
C_{\frac{\text { shipping }}{\text { receiving }}}=(N-1) c_{m} t_{\text {pallet }} \mu
$$

\subsection{Input data}

Input data used in the model were derived from a previous study in the field of the FMCG supply chain, performed by one of the authors. Some details concerning the data collected in the previous work and the case study features are proposed in Appendix. The reader is referred to Bottani \& Rizzi, (2008), for a comprehensive description of the case study.

The data used for the present study are described in the following list.

- The initial value of the inventory level is set at 472 pallets for echelons $1, \ldots N-1$. Such value is derived from the average capacity of a FMCG warehouse (i.e., 500 pallets), which is usually at $80 \%$ saturation;

- the demand distribution is characterized by $\mu=150$ pallets/day and $\sigma=42$ pallets/day. Those values are used under absence of demand "peak"; when "peak" of demand occurs, they are updated to $\mu^{\prime}=300$ pallets/day and $\sigma^{\prime}=59.4$ pallets/day;

- the service level provided by supply chain players, corresponding to the probability to fulfil orders with the available stock, is set at $90 \%$. Consequently, we have $k=1.28$ in eqs.3-4;

- the moving average interval is $m=5$ for distributors and $m=6$ for the retail store;

- $\quad L_{i}$ is set at 4.5 days for all supply chain players, except the manufacturer, whose lead time is 10 days. In both cases, 0.5 days are spent for transport activities;

- $h$ is estimated in approx $153.52 € /$ pallet/year, corresponding to $0.42 € /$ pallet/day, which is derived as the average between costs experienced by distributor and manufacturer;

- the average value of products in the FMCG context accounts for $475 € /$ pallet. It is supposed that each echelon applies $10 \%$ mark-up to this value, which is close to typical 
mark-up for food products (Anderson \& Billou, 2007). Hence, $c_{i}$ in eq.9 varies depending on the echelon considered;

- $\quad c_{o}$ and $c_{t}$ are set at $10 € /$ order and $780 € /$ transport, respectively;

- $C_{\text {shipping/receiving }}$ is estimated in approx $123,187.50$ €/year/echelon under absence of demand "peak" and for 185,287.50 €/year/echelon when demand "peak" is considered;

- $\Delta t$, computed starting from the parameters described above, accounts for 5 days under absence of demand "peak", and is changed to 3 days when demand "peak" is observed.

\section{Results and discussion}

The simulation duration was set at $N_{\text {days }}=365$ days. For each scenario, 25 replications were performed. This value was observed to allow reaching stabilization of the simulation outputs for echelon $N$. As an example of stabilization of model outputs, FIGURE 4 shows the number of orders received by echelon $N$ under "EOQ-5-no_sharing-no_peak" scenario as a function of the number of replications.

\section{INSERT FIGURE 4}

Bullwhip effect results are detailed in TABLE 2, and graphically illustrated in FIGURE 5, in terms of standard deviation ratio $\left(\sigma_{N} / \sigma\right)$, instead of variance ratio, to simplify the representation. TABLE 3 and FIGURE 6 provide a detailed illustration of the costs resulting in the scenarios examined. Statistical analysis of outcomes was also performed, with the aim to identify and assess single and combined effects of the supply chain parameters on the simulation results. The procedure described by Montgomery \& Runger, (2003), was followed to this extent. Outcomes, in terms of Sum of Squares (SS), Mean Square $(M S), F$-test and corresponding significance value (sig.) are proposed in TABLE 4. It should be noted that this analysis is limited to 20 scenarios, resulting from the following combinations of factors:

- reorder policy (factor A) - EOQ (low) or EOI (high); 
- number of supply chain echelons (factor B) - 3 (low) or 5 (high);

- demand information sharing (factor C) - absence (low) or presence (high) of information sharing mechanisms;

- demand behaviour (factor D) - absence (low) or presence (high) of demand "peak";

- responsiveness (factor E) - non responsive (low) or responsive (high) supply chain players. This factor is only considered in conjunction with demand peak (D) under EOI (A) inventory management policy, according to the previous description.

FIGURE 7\%FIGURE 10 join the total costs with the bullwhip effect results; outcomes are shared into four quadrants, resulting from the combination of high/low values of total costs/bullwhip effect ${ }^{1}$. Dots in FIGURE $7 \div$ FIGURE 10 represent the scenarios examined; the corresponding percentage values of total cost and bullwhip effect are proposed in TABLE 5. For each quadrant, the percentage sharing of number of supply chain players (FIGURE 7), inventory management policies (FIGURE 8), information sharing mechanisms (FIGURE 9) and demand behaviour (FIGURE 10) is displayed.

INSERT TABLE $2 \div$ TABLE 5 and FIGURE $5 \div$ FIGURE 10

\subsection{Bullwhip effect results}

To validate the model outcomes, the bullwhip effect values from the simulation runs were compared with those resulting from the application of the analytical approach by Chen et al., (2000). Specifically, the authors derived a lower bound for the variance amplification for echelon $i$, expressed as:

$$
\frac{\sigma^{2}\left(o_{i}\right)}{\sigma^{2}(d)} \geq 1+\frac{2\left(\sum_{k=1}^{i} L_{k}\right)}{m}+\frac{2\left(\sum_{k=1}^{i} L_{k}\right)^{2}}{m^{2}}
$$

\footnotetext{
${ }^{1}$ For visualization purpose, boundaries to the high/low values of both costs and bullwhip effect were set at $12.5 \%$ of the maximum observed value.
} 
Result 1: other things being equal, the bullwhip effect in higher under EOI than under EOQ inventory management policy.

This result was expected; in fact, under an EOI policy, orders are placed at a defined time interval $\Delta t$, while the quantity ordered is null in other periods. As a result, an amplification of the demand variance is observed by the supplier. This confirms a similar result by Jakšič \& Rusjan, (2008), which observed that "order-up-to" replenishment rules induce higher bullwhip effect than others inventory management policies. Outcomes from TABLE 4 also show that the impact of factor A on the resulting bullwhip effect is statistically significant at $p<0.05$.

Result 2: other things being equal, the bullwhip effect is greater when the number of supply chain players increase.

Again, this result was expected, as it is a direct consequence of the bullwhip effect definition (see eq.13). As can be seen from TABLE 4, statistical analyses show a significant $(p<0.05)$ 
impact of number of factor B on the resulting bullwhip effect. FIGURE 7 shows that supply chains with high bullwhip effect and high total costs encompass 4 (43\%) or 5 (57\%) echelons, while supply chains with high bullwhip effect and low total costs are composed of $3(50 \%)$ or 4 (50\%) echelons.

From TABLE 2 it can also be noted that the number of supply chain players substantially increase the bullwhip effect under absence of information sharing; conversely, under information sharing, outcomes of the simulation runs support this result to a lower extent. In this regard, focusing on TABLE 4, it can be appreciated that the combined effect of demand information sharing and number of supply chain players (i.e. factors BC) has not significant impact on the bullwhip effect. This could be explained considering that complete supply chain visibility provides, as output, substantially lower demand amplification; consequently, most of the resulting scenarios are characterised by similar values of the bullwhip effect, regardless of the number of echelons.

Outcomes of TABLE 4 also suggest that the combined implementation of EOI inventory management policy and high number of supply chain echelons (i.e., factors $A B$ ) has a significant $(p<0.05)$ impact on the resulting bullwhip effect. As explained in result 1 , under an EOI policy, several "null" orders are observed, as supply chain players place orders every $\Delta t$. In particular, as the $O U L_{t, i}$ is computed according to the orders received (see eqs.1 and 3), under this scenario it is found that, due to substantial demand variance amplification, orders to echelon $N$ are very limited in number. Conversely, quantities ordered are dramatically increased. This effect is particularly evident for high $N$.

Result 3: other things being equal, the bullwhip effect is greater under absence of information sharing. 
Result 4: under some circumstances, the bullwhip effect is lower when a "peak" of demand is introduced in the supply chain.

Outcomes from TABLE 4 show that the single effect of the "peak" of demand against the bullwhip effect is not statistically significant ( $p>0.05)$; this suggests that the demand "peak", per $s e$, does not significantly affect the observed bullwhip effect. In this regard, it can be seen from FIGURE 10 that high bullwhip effect may occur either under presence or absence of demand "peak". From the same figure, it is also interesting to note that high bullwhip effect combined with low total cost always occur under absence of demand "peak" (100\% of the scenarios examined).

The combined introduction of demand "peak" and EOI inventory management policy (i.e., factors $\mathrm{AD}$ ), as well as of demand "peak" and high number of supply chain players (i.e., factors BD), have significant impact on the resulting bullwhip effect. Specifically, outcomes in TABLE 2 indicate that a lower bullwhip effect is usually observed when demand "peak" is introduced in the model. The same result is indicated in FIGURE 8, which shows that scenarios with high bullwhip effect and high total costs are mainly characterised by EOI policy (86\% of the 
scenarios examined), while EOI and EOQ policies are equally shared in scenarios with high bullwhip effect and low total costs.

From an operational perspective, this result could be explained considering that, when an unexpected increase in demand is observed, a supply chain player tends to increase the number of orders placed. Under an EOI policy, this involves reducing the ordering interval $\Delta t$; consequently, a lower number of "null" orders are observed. From the computational point of view, a lower order variance emerges. This effect is particularly emphasised when $N=5$, as can be seen from FIGURE 7.

Result 5: under "peak" of demand, the bullwhip effect is lower if the supply chain is able to quickly react to the demand variation.

This result is evident from numerical outcomes in TABLE 2, as all "responsive" scenarios show a lower bullwhip effect than the corresponding "non responsive" ones. A reactive supply chain player is able to quickly update the reorder policy parameters (i.e., the order interval $\Delta t$ ), which results in the capability to better follow the demand trend, avoiding to introduce additional variability. Nonetheless, it should be noted that no statistical evidence can be provided in this regard.

\subsection{Costs analysis}

Outcomes from cost analysis can be summarized in the following key points.

Result 6: the total costs observed under scenarios "EOI-5-no_sharing-peak-no_resp”, "EOI-5no_sharing-no_peak", and "EOI-5-no_sharing-peak-resp" are significantly higher than all the remaining scenarios. 
This result was derived from the analysis of outcomes in TABLE 3. The above scenarios are all composed of 5 echelons, and operate under EOI policy and absence of information sharing. The resulting costs ranges from about 15 to 19 million $€ /$ year, while all other scenarios experience costs lower than 7 million $€ /$ year. It can be easily noted that the costs are almost entirely due to stocks, which account for $83.2 \%$ (under "EOI-5-no_sharing-peak-resp" scenario) to $86.8 \%$ (under "EOI-5-no_sharing-peak-no_resp" scenario) of the total costs. This result, in turn, is a consequence of the bullwhip effect observed, ranging from 53.24 to 108.4 in terms of $\sigma_{N} / \sigma$ for the scenarios considered (see TABLE 2), which involves high safety stock levels. In particular, looking at FIGURE 8 and FIGURE 9, one can see that high bullwhip effect combined with high total costs is mainly observed under EOI policy ( $86 \%$ of the scenarios examined) and absence of information sharing mechanisms (100\% of the scenarios examined).

Result 7: other things being equal, the total costs observed are significantly higher when the number of supply chain players increase.

The number of supply chain echelons has the highest impact on the observed total costs of the supply chain $(p=0.000)$. In particular, statistically significant effects of factor B are observed against all cost components considered in this study. FIGURE 7 confirms that supply chain configurations with high costs are only composed of 4 or 5 echelons.

This is an obvious result, since the increase in the number of supply chain echelons clearly involves increase in all cost components considered, due to the need of adding the cost contributions of each echelon (see eqs.8-12).

Result 8: other things being equal, the total costs observed are significantly higher under EOI than EOQ inventory management policy. 
This result, which is supported from previous studies by Chopra \& Meindl, (2004), can be observed from outcomes in TABLE 4, indicating a high significance of factor A on the resulting total costs $(p<0.05)$. Overall, statistical analyses indicate that factor A substantially affects most of the costs components examined, except stock-out costs, and that its impact is statistically significant at $p<0.05$. In this regard, FIGURE 8 highlights that high costs coupled by high bullwhip effect are mainly observed under EOI rather than EOQ policy ( $86 \%$ vs. $14 \%$ of the scenarios examined), while EOI and EOQ are equally shared in scenarios experiencing high cost with low bullwhip effect.

As mentioned already, EOI policy usually involves a higher average stock level, as a consequence of the lower number of orders, with wider quantities. This is confirmed by statistical analyses performed, which highlight a significant impact $(p=0.002)$ of factor A on the resulting costs of holding stocks. As order and transport costs are both computed starting from the number of orders (see eqs.11-12), the statistically significant impact of EOI inventory management policy on those cost components is a direct consequence of the number of orders placed by supply chain players under that policy.

As a further outcome, the combined effect of factors $\mathrm{AB}$ (i.e., EOI policy coupled with high number of supply chain echelons) is also found to significantly impact the total costs. Specifically, it is reasonable that factors $\mathrm{AB}$ substantially increase each cost component examined, since both the number of echelons and the EOI policy involve a significant increase of the cost components. This is confirmed by results in TABLE 3 .

Result 9: other things being equal, the total costs observed tend to be lower when demand information sharing is introduced. However, demand information sharing has a different impact on each cost component. 
From TABLE 3, TABLE 4 and FIGURE 9, it can be appreciated that total costs observed are usually lower when demand information sharing mechanisms are introduced, and that the effect is statistically significant at $p=0.001$.

This result is a consequence of several effects. As a first point, it can be observed from TABLE 3 that costs of holding stocks are substantially lower under demand information sharing. In fact, as mentioned in result 3 , the availability of POS data allows reducing the orders variability, resulting in a lower bullwhip effect and in a significant reduction of the amount of stocks required at each supply chain echelon. In this regard, a significant impact $(p=0.000)$ of demand information sharing mechanisms on the resulting costs of holding stocks is observed in TABLE 4. Although this is a general result, it can be particularly appreciated when examining a 5echelon supply chain, where the resulting bullwhip effect is extremely high (see TABLE 2 and result 2).

Conversely, results presented in TABLE 3 indicate that stock-out costs tend to increase when demand information sharing is implemented, although the availability of POS data, per se, has no significant effect $(p=0.055)$ on the observed stock-out costs. This result should mainly be ascribed to the way stock-out costs were modelled in our study. In fact, under demand information sharing, each supply chain player places orders based on POS data; hence, quantities ordered are usually lower than those required under unknown customer's demand, resulting in reduced average stock level. However, under stochastic demand it is always possible that demand values (and consequently orders placed) exceed the amount of stocks available; this is exacerbated when the average stock level is lower. Consequently, stock-out costs increase under demand information sharing mechanism.

Finally, demand information sharing mechanisms appear to significantly affect the observed order $(p=0.003)$ and transport $(p=0.003)$ costs. Looking at TABLE 3, it can be seen that, in particular, demand information sharing tends to increase the resulting order and transport costs. In fact, the availability of POS data allows reducing the observed demand variability, allowing 
orders placed to better follow the demand behaviour: specifically, lower quantities are ordered more frequently, with a resulting increase in the number of orders placed.

The combined effect of the above described cost components leads to very different results, depending on the supply chain configuration examined. More precisely, it can be seen from FIGURE 6 and TABLE 3 that costs of holding stocks are by far the most important cost component of 5-echelon supply chains. Demand information sharing thus involves a significant decrease of costs for those supply chains. An opposite situation occurs for 3-echelon supply chains. In fact, given the low number of echelons, this supply chain configuration is affected by costs of holding stocks and stock-out costs to a similar extent: such costs account for about $35 \%$ and $37 \%$ on the total costs, respectively. By amplifying the stock-out costs, information sharing leads to a slight increase of the total costs for those scenarios. Finally, 4-echelon supply chain scenarios appear to be closer to 5-echelon ones, i.e. information sharing involves decrease in the total costs; however, due to the lower number of echelons, this result is less evident.

Besides the above result, outcomes of the statistical analysis and economical assessment also show that demand information sharing mechanisms, in conjunction with EOI policy and high number of supply chain echelons (i.e. factors $\mathrm{ABC}$ ), appear to significantly affect the observed order $(p=0.005)$ and transport $(p=0.007)$ costs, and in particular tend to increase such costs. This is again a consequence of the increased number of orders placed, resulting from the reduced demand variability and corresponding decrease of quantities per order.

Result 10: other things being equal, the total costs observed increase when "peak" of demand is introduced.

Results in TABLE 3, TABLE 4 and FIGURE 10 indicate that total supply chain costs are higher when "peak" of demand is introduced, and that the impact of demand "peak" (i.e., factor D) on the observed costs is significant at $p=0.012$. More precisely, demand "peak" involves increase 
of stock-out $(p=0.005)$, order $(p=0.000)$, transport $(p=0.000)$, and shipping/receiving $(p=0.000)$ costs, resulting in substantially higher total costs.

The increase of stock-out costs was expected, since, as a consequence of demand "peak", the amount of stock available for each supply chain player is more likely to be lower than the quantity requested. Moreover, as already discussed, when a demand increase is introduced, a supply chain player tends to increase the number of orders placed, regardless of the inventory management policy applied. Hence, an increase in order costs and corresponding transport costs is observed. Finally, due to the computational procedure followed, shipping/receiving costs are amplified as a consequence of the increased quantity of pallets handled per year.

The combined effect of factors AD (i.e., demand peak and EOI inventory management policy) on the total costs, and in particular on the costs of holding stocks, is also significant. It can be observed from TABLE 3 that cost of holding stocks tends to increase under peak of demand and EOI policy. This result should be ascribed to the increased order variance caused by demand peak under EOI inventory management policy, which, in turn, involves increase in the required safety stocks for each echelon.

Similar considerations can be drawn for the combined effect of factors BD (i.e., demand "peak" coupled with high number of supply chain echelons) on the total costs. More precisely, factors BD significantly affect the resulting costs of holding stocks $(p=0.000)$, orders $(p=0.031)$ and transport ( $p=0.036)$. From TABLE 3 , it can be seen that all the above costs components tend to be higher when examining 5-echelon supply chains under demand "peak". As previously mentioned, the higher order variance caused by demand "peak" involves increase in the required safety stocks for each supply chain echelon, resulting in a corresponding increase in their costs. Demand "peak" also involves an increase in the number of orders placed, due to higher demand observed. Order and transport costs are thus amplified correspondingly. 
Result 11: other things being equal, under "peak" of demand, the total costs observed decrease if the supply chain is able to quickly react to the demand variation.

It can be seen from TABLE 4 that the combined effect of demand "peak" and responsiveness, under EOI inventory management policy (i.e., factors ADE) has a significant impact $(p=0.03)$ on the resulting total costs observed. In fact, a quick reaction of the supply chain implies that each player updates inventory management parameters (in particular, the $\Delta t$ interval) immediately after the demand "peak" is observed. The main outcome of such reaction is that the average stock level is quickly adapted to the new demand value, thus optimizing the overall cost of stocks. Outcomes from TABLE 4 also highlight that the combined effect of factors ADE significantly decreases the resulting stock-out $(p=0.034)$, order $(p=0.000)$, transport $(p=0.000)$ and shipping/receiving $(p=0.001)$ costs. As a result, the observed total costs decrease under this scenario.

\section{Conclusions}

Based on a discrete-event simulation model, reproducing a Fast Moving Consumer Goods (FMCG) supply chain, we have provided a quantitative assessment of the effects of different configurations on the total costs and bullwhip effect observed in the supply chain. Our analysis covers 30 possible supply chain configurations, resulting from the combination of several design parameters, such as number of echelons, reorder policy adopted, demand information sharing mechanisms, demand behaviour, and responsiveness. For each scenario, total costs and bullwhip effect were computed starting from simulation outcomes and several input parameters available in literature. Moreover, a statistical analysis of effects was performed to identify possible significant impact of single/combined supply chain design parameters on the resulting costs and demand variance amplification.

The key results of this study show that both the total logistics cost and the bullwhip effect are affected by all supply chain design parameters examined, although to a different extent. In 
particular, the number of supply chain echelons and the implementation of an EOI inventory management policy involve a substantial increase in the total costs and bullwhip effect, and their impact is significant at $p<0.05$. The presence of demand "peak" also causes an increase in the total logistics costs, although, per se, it does not significantly affect the resulting bullwhip effect. Conversely, demand information sharing mechanisms tend to reduce both the bullwhip effect and the resulting total costs, due to the significant $(p=0.000)$ decrease in costs of holding stocks.

As the simulation model was developed using average data of the FMCG context, our results can be useful in practice to identify the optimal supply chain configuration as a function of the operating conditions. Moreover, outcomes from this study provide some insights about the supply chain cost components and their trend depending on the configuration considered.

Our study is grounded on the simulation of a single-product flow. To derive more general results, it would be appropriate to extend the model to include: (1) the flow of different products, with different characteristics; (2) several supply chain players per echelon; (3) leadtime stochasticity and corresponding order crossover investigation; and (4) a sensitivity analysis of model outcomes as a function of different values of the input parameters.

\section{References}

Anderson, J. and Billou, N., 2007. Serving the world's poor: innovation at the base of the economic pyramid, Journal of Business Strategy, 28(2), 14-21

Bottani, E. and Rizzi, A., 2008. Economical assessment of the impact of RFID technology and EPC system on the Fast Moving Consumer Goods supply chain. International Journal of Production Economics, 112(2), 548-569

Bottani, E., Montanari, R. and Volpi, A., 2007. Quantifying the Bullwhip Effect in inventory management policies. Proceedings of the $12^{\text {th }}$ International Symposium in Logistics, Budapest (Hungary)

Bowersox, J., and Closs, D.J., 1996. Logistical management. McGraw-Hill, New York

Chan, F.T.S. and Chan, H.K., 2005. Simulation modeling for comparative evaluation of supply chain management strategies. Journal of Advanced Manufacturing Technology, 25, 998-1006. 
Chatfield, D.C., Kim, J.G., Harrison, T. P. and Hayya, J.C., 2004. The Bullwhip Effect-Impact of Stochastic Lead Time, Information Quality, and Information Sharing: A Simulation Study. Production and Operations Management 13(4), 340-353

Chen, F., Drezner, Z., Ryan, J.K. and Simchi-Levi, D., 2000. Quantifying the bullwhip effect in a simple supply chain: the impact of forecasting, lead time, and information. Management Science 46(3), 436-443

Chopra, S. and Meindl, P., 2004. Supply chain management: Strategy, planning and operations (2 ${ }^{\text {nd }}$ edition). Prentice Hall, Upper Saddle River, NJ

Cooper, M.C., Lambert, D.M. and Pagh, J.D., 1997. Supply chain management: More than a new name for logistics. The International Journal of Logistics Management, 8(1), 1-13

Dejonckheere, J., Disney, S.M., Lambrecht, M.R. and Towill, D.R., 2003. Measuring and avoiding the bullwhip effect: A control theoretic approach. European Journal of Operational Research 147, 567-590

Hammami, R., Frein, Y. and Hadj-Alouane, A.B., 2008. Supply chain design in the delocalization context: Relevant features and new modeling tendencies. International Journal of Production Economics, 113(2), 641-656

Harrison J.R., Lin Z., Carroll G.R. and Carley K.M., 2007. Simulation modeling in organizational and management research. Academy of Management Review, 32(4), 1229-1245

Higuchi, T. and Troutt, M.D., 2004. Dynamic simulation of the supply chain for a short life cycle product—Lessons from the Tamagotchi case. Computers \& Operations Research, 31, 1097-1114

Hwarng, H.B., Chong, C.S.P., Xie, N. and Burgess, T.F., 2005. Modelling a complex supply chain: understanding the effect of simplified assumptions. International Journal of Production Research, 43(13), 2829-2872

Iannone, R., Miranda, S. and Riemma, S., 2007. Supply chain distributed simulation: An efficient architecture for multi-model synchronization. Simulation Modelling Practice and Theory, 15, 221-236

Jakšič, M., and Rusjan, B., 2008. The effect of replenishment policies on the bullwhip effect: A transfer function approach. European Journal of Operational Research, 184, 946-961

Lambert, D.M., 2001. The supply chain management and logistics controversy. In Brewer, A., Button, K.J., Hensher, D.A., (Eds.), Handbook of Logistics and Supply Chain Management. Pergamon, Oxford

Lau, J.S.K., Huang, G.Q. and Mak, K.L., 2004. Impact of information sharing on inventory replenishment in divergent supply chains. International Journal of Production Research 42(5), 919-941

Lee, H.L., Padmanabhan, V., and Whang, S., 2004. Information distortion in the supply chain: the bullwhip effect. Management Science 50(12), 1875-1886

Lee, H.L., So K.C., and Tang, C.S., 2000. The value of information sharing in a two-level supply chain. Management Science, 46(5), 626-643

Lowson, B., King, R., and Hunter, A., 1999. Quick Response: Managing the Supply Chain to Meet Customer Demand. John Wiley \& Sons, Chichester

Longo, F., and Mirabelli, G., 2008. An advanced supply chain management tool based on modeling and simulation. Computers \& Industrial Engineering, 54, 570-588

Montgomery, D.C., and Runger G.C., 2003. Applied Statistics and Probability for Engineers (3 ${ }^{\text {rd }}$ Edition). John Wiley \& Sons Inc, USA 
Persson, F. and Araldi, M., 2007. The development of a dynamic supply chain analysis tool—Integration of SCOR and discrete event simulation. International Journal of Production Economics, doi:10.1016/j.ijpe.2006.12.064

Persson, F. and Olhager J., 2002. Performance simulation of supply chain designs. International Journal of Production Economics, 77, 231-245

Reizebos, J., 2006. Inventory order crossover. International Journal of Production Economics, 104, 666-675

Sen, W., Pokharel, S. and YuLei, W., 2004. Supply chain positioning strategy integration, evaluation, simulation, and optimization. Computers \& Industrial Engineering, 46, 781-792

Shang, J.S., Li, S. and Tadikamalla, P., 2004. Operational design of a supply chain system using the Taguchi method, response surface methodology, simulation, and optimization. International Journal of Production Research, 42(18), 3823-3849

Shapiro, J., 2001. Modelling the supply chain. Duxbury Thomson Learning, Pacific Groove, CA

Sun, H.X. and Ren, Y.T., 2005. The impact of forecasting methods on bullwhip effect in supply chain management. Proceedings of the 2005 Engineering Management Conference 1, 215- 219

Zhang, C. and Zhang, C., 2007. Design and simulation of demand information sharing in a supply chain. Simulation Modeling Practice and Theory, 15, 32-46

Zhang, X., 2004. The impact of forecasting methods on the bullwhip effect. International Journal of Production Economics, 88, 15-27

Zhao, X. and Xie, J., 2002. Forecasting errors and the value of information sharing in a supply chain. International Journal of Production Research, 40(2), 311-335 


\section{Appendix: case study details}

The data related to the supply chain considered is this paper were derived from a previous research by Bottani \& Rizzi (2008), in the field of FMCG. In this section, we detail the research methodology followed by the authors and the resulting supply chain data.

The data collection phase involved a panel of 11 enterprises, operating as manufacturers (6 companies) and distributors (5 companies) of FMCG. For each participant, the analysis was focused on a distribution centre (DC), suggested by the company to be enough representative of logistics processes. In addition, for each distributor, a retail store (RS) was identified and investigated. The aim of the analysis was to detail the relevant logistics processes of each participant. To this extent, an appropriate survey phase was carried out, where two different questionnaires have been deployed to collect comprehensive data both for DCs and RSs. In both questionnaires, a first part was aimed at collecting general information about the participant, as well as common data for all processes examined (e.g., products type, average value of pallet/case, number of employees and related costs, DC/RS area). Moreover, specific sections were added to collect data related to the processes performed by DCs and RSs (i.e., "receiving", "putaway", "picking and sorting" and "shipping" for DCs, and "receiving", "backroom management" and "expositive area management" for RSs). For each process, quantitative parameters were examined, such as amount of goods flow, stock levels, amount of safety stock, or stock-outs. A list of quantitative data collected, relevant for the present study, is proposed in the following:

\begin{tabular}{ll}
\hline Quantitative data collected \\
\hline Distribution centres & $\begin{array}{l}\text { Number of pallets/day received; number of orders/day received; number of } \\
\text { receiving bays; average pallet value; storage capacity; average storage }\end{array}$ \\
& saturation; number of fork lift truck; average stock-out; amount of safety \\
& stocks; amount of shrink; number of orders/day fulfilled; number of \\
& pallets/day shipped; orders profile; number of shipping bays; mobile mean \\
& interval; average lead time; number of employees; average hourly cost of \\
& manpower
\end{tabular}



receiving bays; storage capacity; number of fork lift trucks; average pallet value; average stock-out; amount of safety stocks; number of pallet/day sold; mobile mean interval; average lead time; number of employees; average hourly cost of manpower

The data collection phase, together with site visits, approximately took from November 2004 to April 2005; for each visit, about 2-3 hours were spent for visiting the structure and answering the questionnaire.

Starting from the data collected, as many case studies were edited, detailing the processes currently performed by the DC/RS and the corresponding performance. The case studies were used to outline a "representative" FMGC supply chain, on the basis of the similarities between processes analysed. The "representative" supply chain is composed of three echelons, namely a manufacturer's DC, a distributor's DC and a RS. Representative structures are characterised by average features which have been obtained from data collected. Quantitative parameters (e.g., the amount of pallets received or shipped, or the stock level of DCs and retail stores) have been derived as the mathematical average of the data collected, and are exploited in this study as input parameters for the simulation model. 


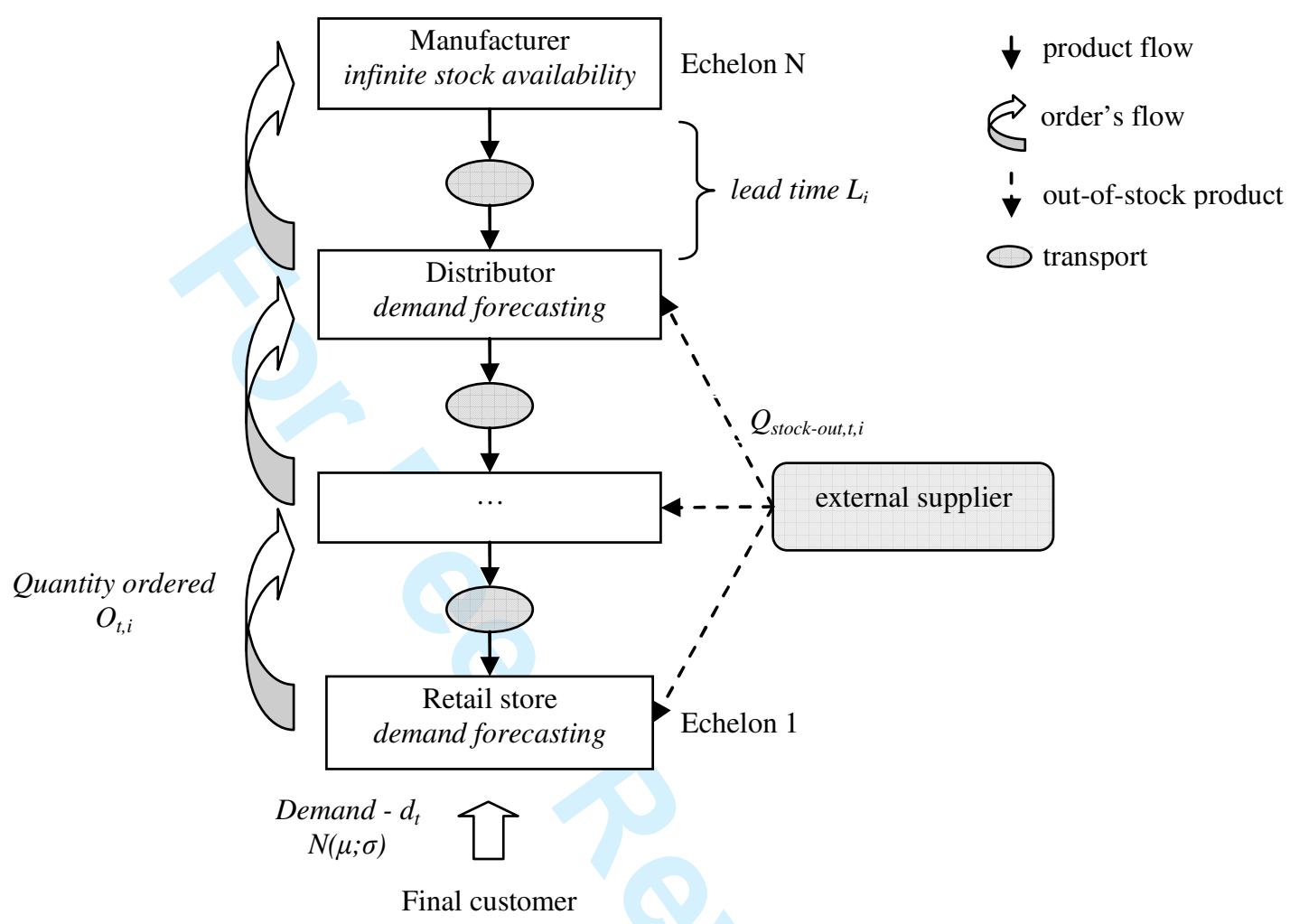

FIGURE 1: qualitative scheme of the model developed under absence of information sharing. 


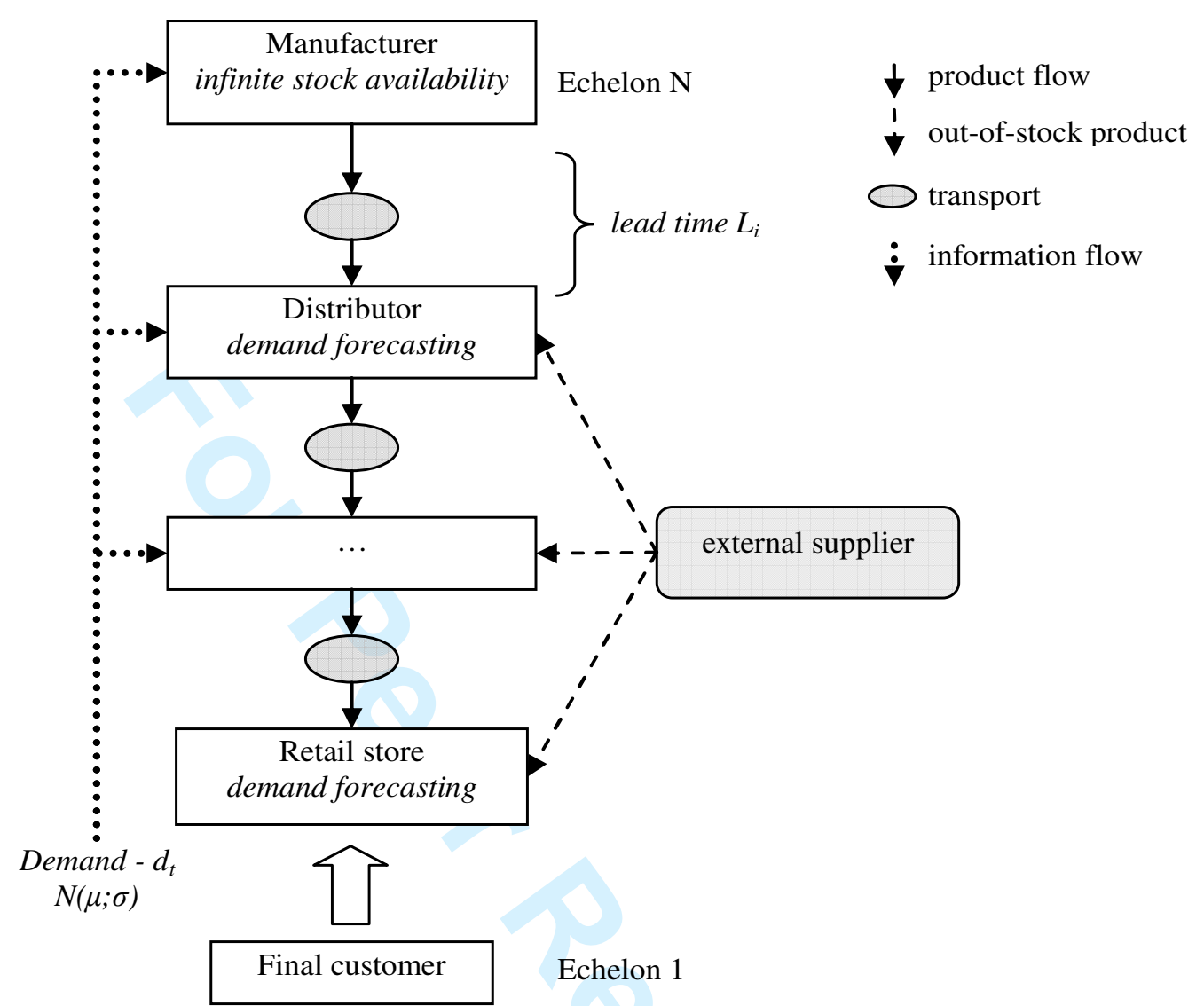

FIGURE 2: qualitative scheme of the model developed under information sharing mechanisms. 


\begin{tabular}{|c|c|c|c|c|}
\hline \multirow{12}{*}{ EOQ policy } & \multirow{4}{*}{3} & \multirow{2}{*}{ no information sharing } & no peak of demand & \\
\hline & & & peak of demand & \\
\hline & & \multirow{2}{*}{ information sharing } & no peak of demand & \\
\hline & & & peak of demand & \\
\hline & \multirow{4}{*}{4} & \multirow{2}{*}{ no information sharing } & no peak of demand & \\
\hline & & & peak of demand & \\
\hline & & \multirow{2}{*}{ information sharing } & no peak of demand & \\
\hline & & & peak of demand & \\
\hline & \multirow{4}{*}{5} & \multirow{2}{*}{ no information sharing } & no peak of demand & \\
\hline & & & peak of demand & \\
\hline & & \multirow{2}{*}{ information sharing } & no peak of demand & \\
\hline & & & peak of demand & \\
\hline \multirow{18}{*}{ EOI policy } & \multirow{6}{*}{3} & \multirow{3}{*}{ no information sharing } & no peak of demand & \\
\hline & & & \multirow{2}{*}{ peak of demand } & responsive \\
\hline & & & & non-responsive \\
\hline & & \multirow{3}{*}{ information sharing } & no peak of demand & \\
\hline & & & \multirow{2}{*}{ peak of demand } & responsive \\
\hline & & & & non-responsive \\
\hline & \multirow{6}{*}{4} & \multirow{3}{*}{ no information sharing } & no peak of demand & \\
\hline & & & \multirow{2}{*}{ peak of demand } & responsive \\
\hline & & & & non-responsive \\
\hline & & \multirow{3}{*}{ information sharing } & no peak of demand & \\
\hline & & & \multirow{2}{*}{ peak of demand } & responsive \\
\hline & & & & non-responsive \\
\hline & \multirow{6}{*}{5} & \multirow{3}{*}{ no information sharing } & no peak of demand & 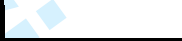 \\
\hline & & & \multirow{2}{*}{ peak of demand } & responsive \\
\hline & & & & non-responsive \\
\hline & & \multirow{3}{*}{ information sharing } & no peak of demand & \\
\hline & & & \multirow{2}{*}{ peak of demand } & responsive \\
\hline & & & & non-responsive \\
\hline
\end{tabular}

EOQ-3-no_sharing-no_peak EOQ-3-no_sharing-peak EOQ-3-sharing-no_peak EOQ-3-sharing-peak EOQ-4-no_sharing-no_peak EOQ-4-no_sharing-peak EOQ-4-sharing-no_peak EOQ-4-sharing-peak EOQ-5-no sharing-no peak EOQ-5-no_sharing-peak EOQ-5-sharing-no_peak EOQ-5-sharing-peak

EOI-3-no_sharing-no_peak EOI-3-no_sharing-peak-resp EOI-3-no_sharing-peak-no_resp EOI-3-sharing-no_peak EOI-3-sharing-peak-resp EOI-3-sharing-peak-no_resp EOI-4-no_sharing-no_peak EOI-4-no_sharing-peak-resp EOI-4-no_sharing-peak-no_resp EOI-4-sharing-no_peak EOI-4-sharing-peak-resp EOI-4-sharing-peak-no_resp EOI-5-no_sharing-no_peak EOI-5-no_sharing-peak-resp EOI-5-no_sharing-peak-no_resp EOI-5-sharing-no_peak EOI-5-sharing-peak-resp EOI-5-sharing-peak-no_resp

FIGURE 3: scenarios examined during simulation runs. 


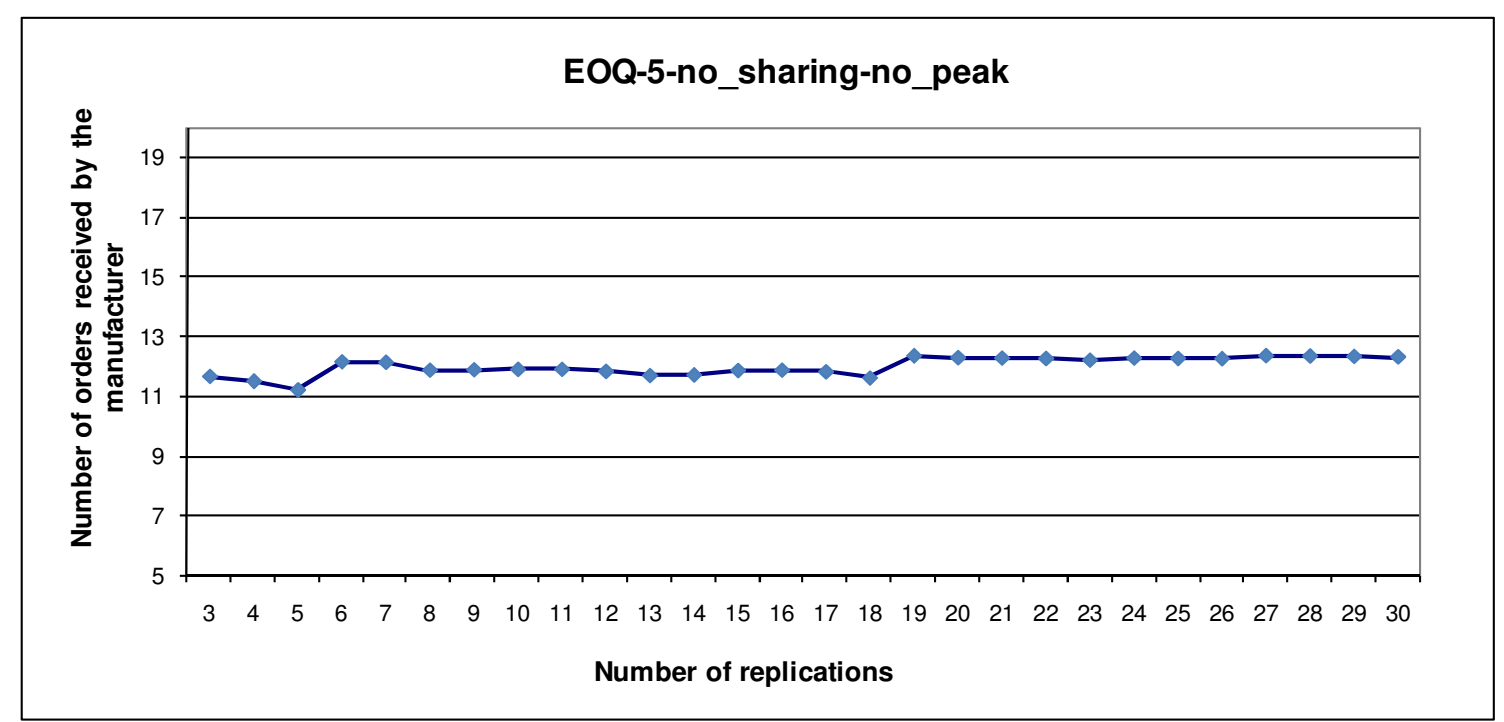

FIGURE 4: number of orders received by the manufacturer as a function of the number of replications. 


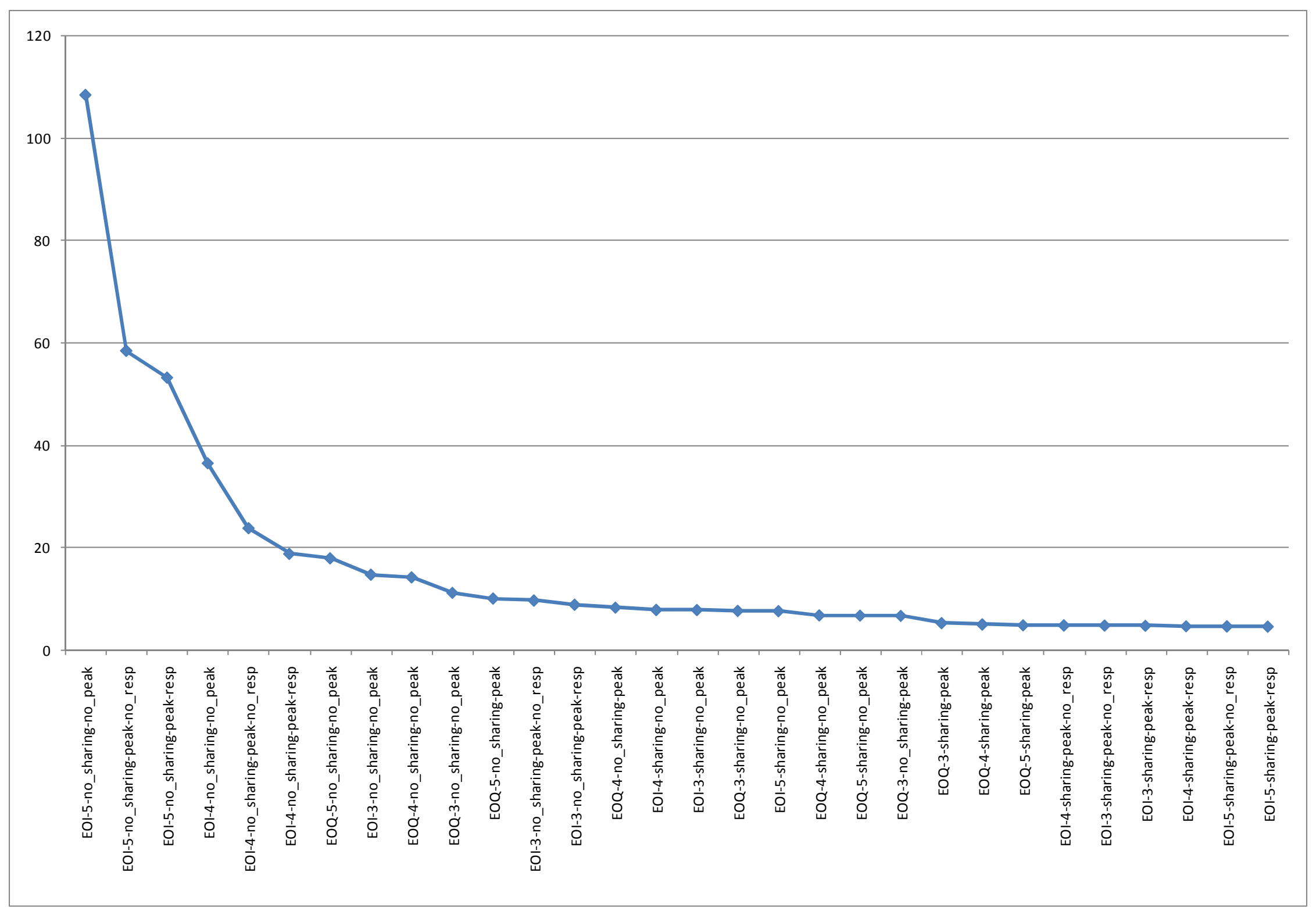

FIGURE 5: Bullwhip effect $\left(\sigma_{N} / \sigma\right)$ for the scenarios examined. 


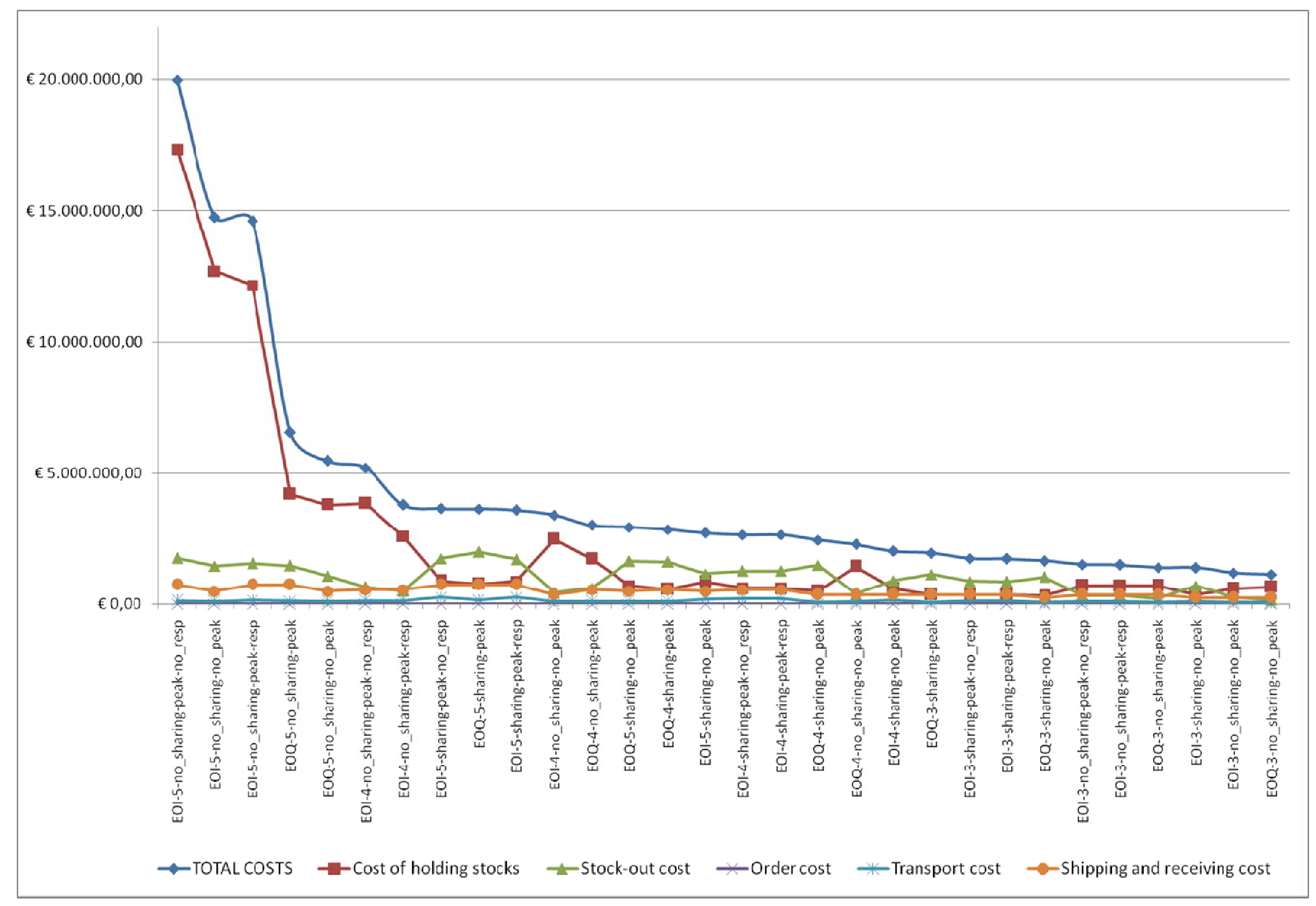

FIGURE 6: total costs for the scenarios examined. 


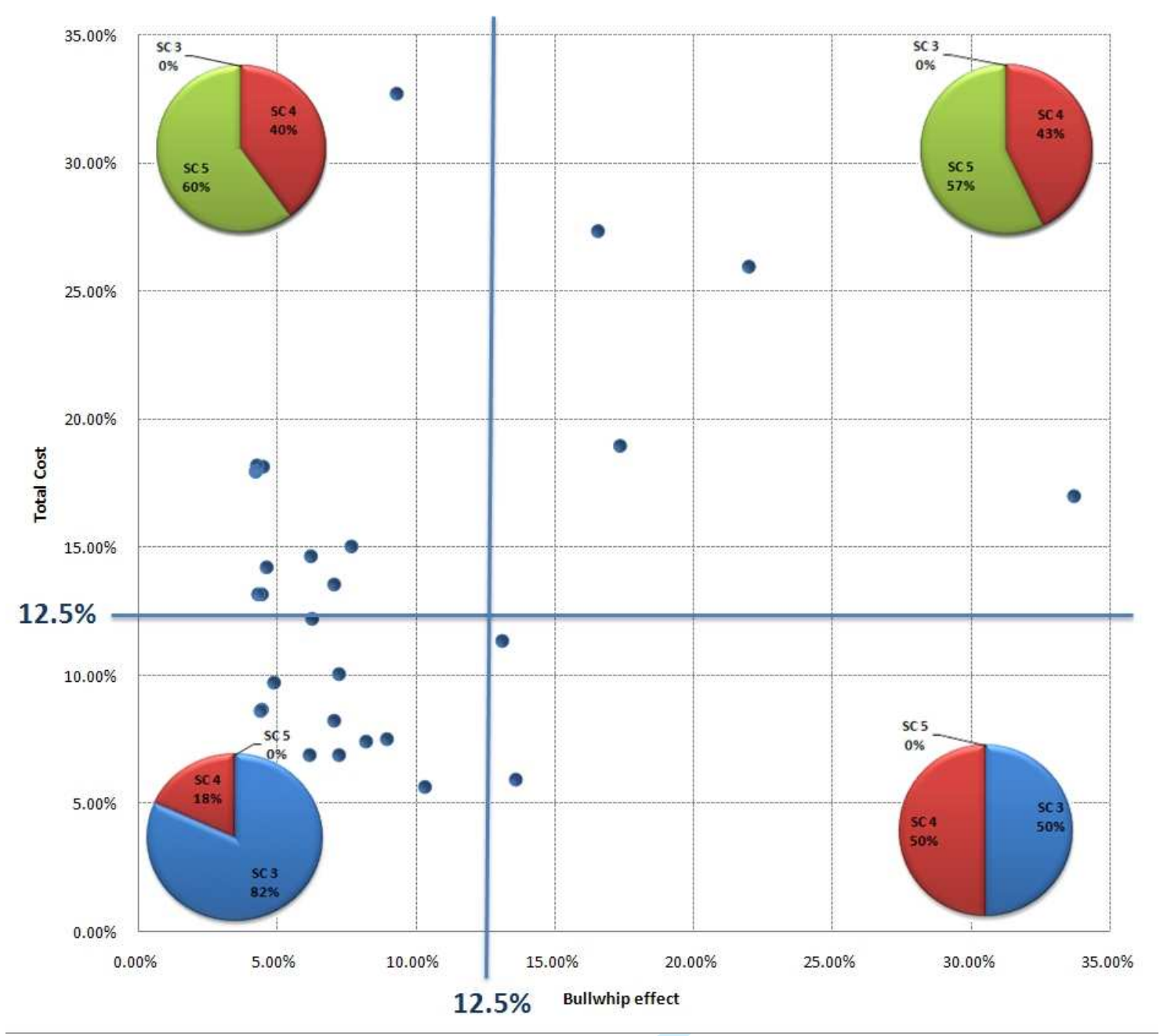

FIGURE 7: supply chain structure as a function of total costs and bullwhip effect. 


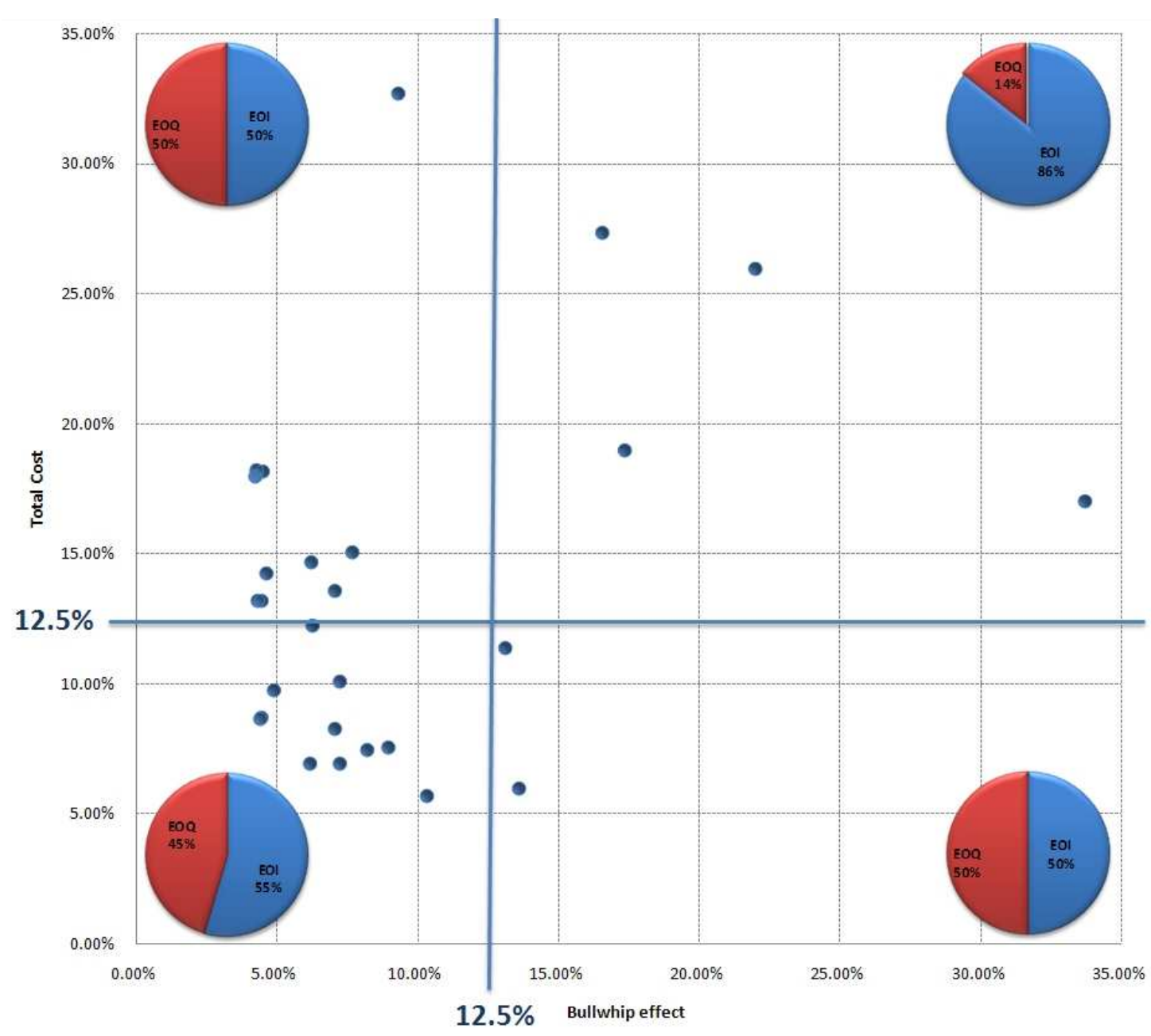

FIGURE 8: reorder policy as a function of total costs and bullwhip effect. 


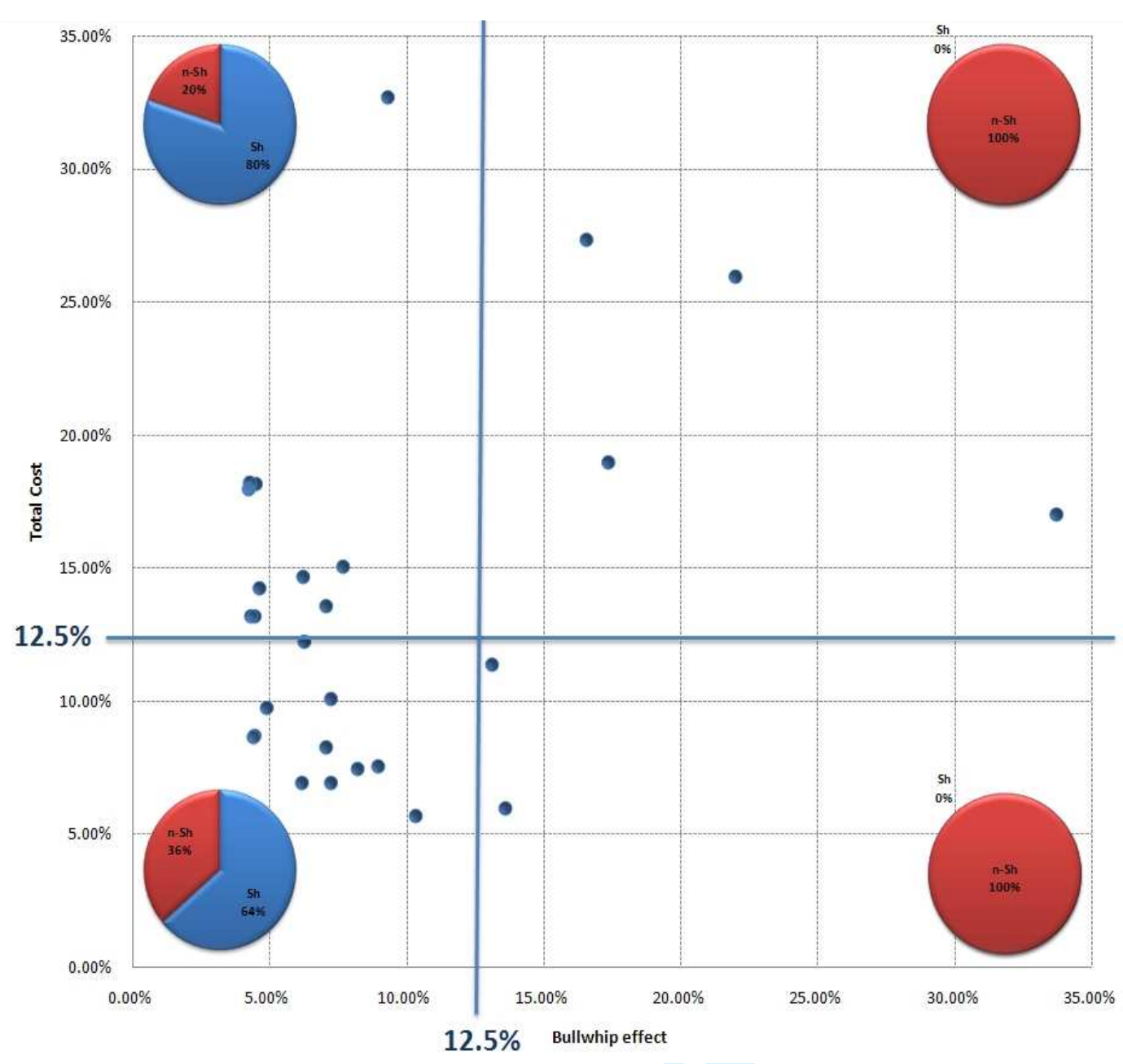

FIGURE 9: information sharing mechanisms as a function of total costs and bullwhip effect (Note: $s h=$ information sharing; $\mathbf{n}$-sh = no information sharing). 


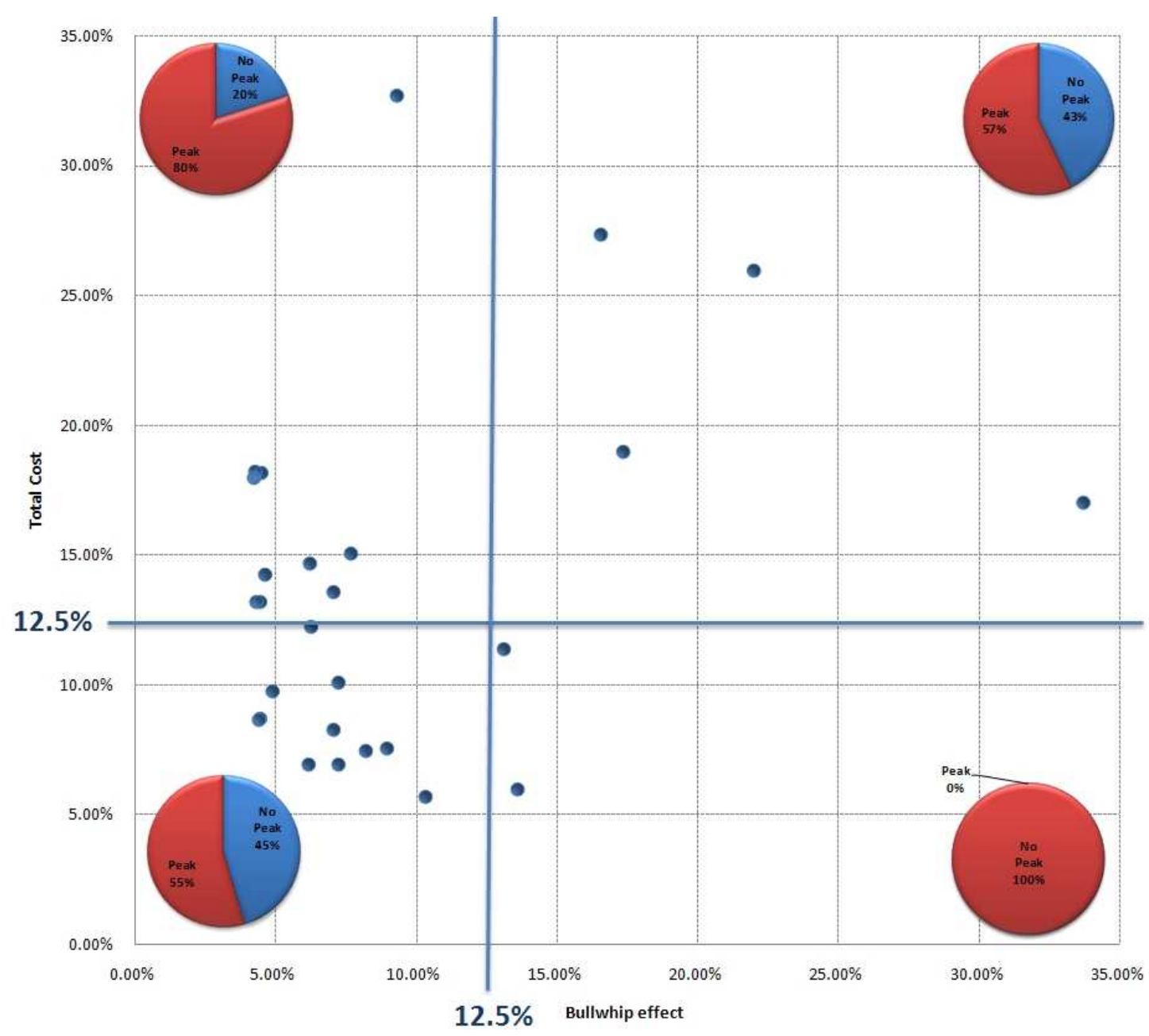

FIGURE 10: demand behaviour as a function of total costs and bullwhip effect. 
TABLE 1: nomenclature used to detail the model

\begin{tabular}{lcc}
\hline \multicolumn{1}{c}{ Parameter } & Acronym & Measurement unit \\
\hline \multicolumn{1}{c}{ Simulation model } & & \\
\hline Number of supply chain echelons & $N(i=1, \ldots N)$ & - \\
Simulation duration & $N_{\text {days }}$ & days \\
Lead time of the $i$-th echelon & $L_{i}$ & days \\
\hline \multicolumn{1}{l}{ Final customer's demand parameters } & & \\
\hline Mean & $\mu$ & pallets/day \\
Standard deviation & $\sigma$ & pallets/day \\
Daily final customer's demand value at time $t$ & $d_{t}$ & pallets/day
\end{tabular}

\begin{tabular}{llc}
\hline \multicolumn{1}{c}{ Demand forecasting for echelon $\boldsymbol{i}$} & & \\
$(\boldsymbol{i}=\mathbf{1}, \ldots \boldsymbol{N}-\mathbf{1})$ & $m$ & days \\
\hline Moving average interval & $\mu_{t, i}$ & pallets/day \\
Estimated demand mean at day $t$ & $\sigma_{t, i}$ & pallets/day \\
Estimated demand standard deviation at day $t$ & $d_{i, t}$ & pallets/day \\
Demand faced at time t &
\end{tabular}

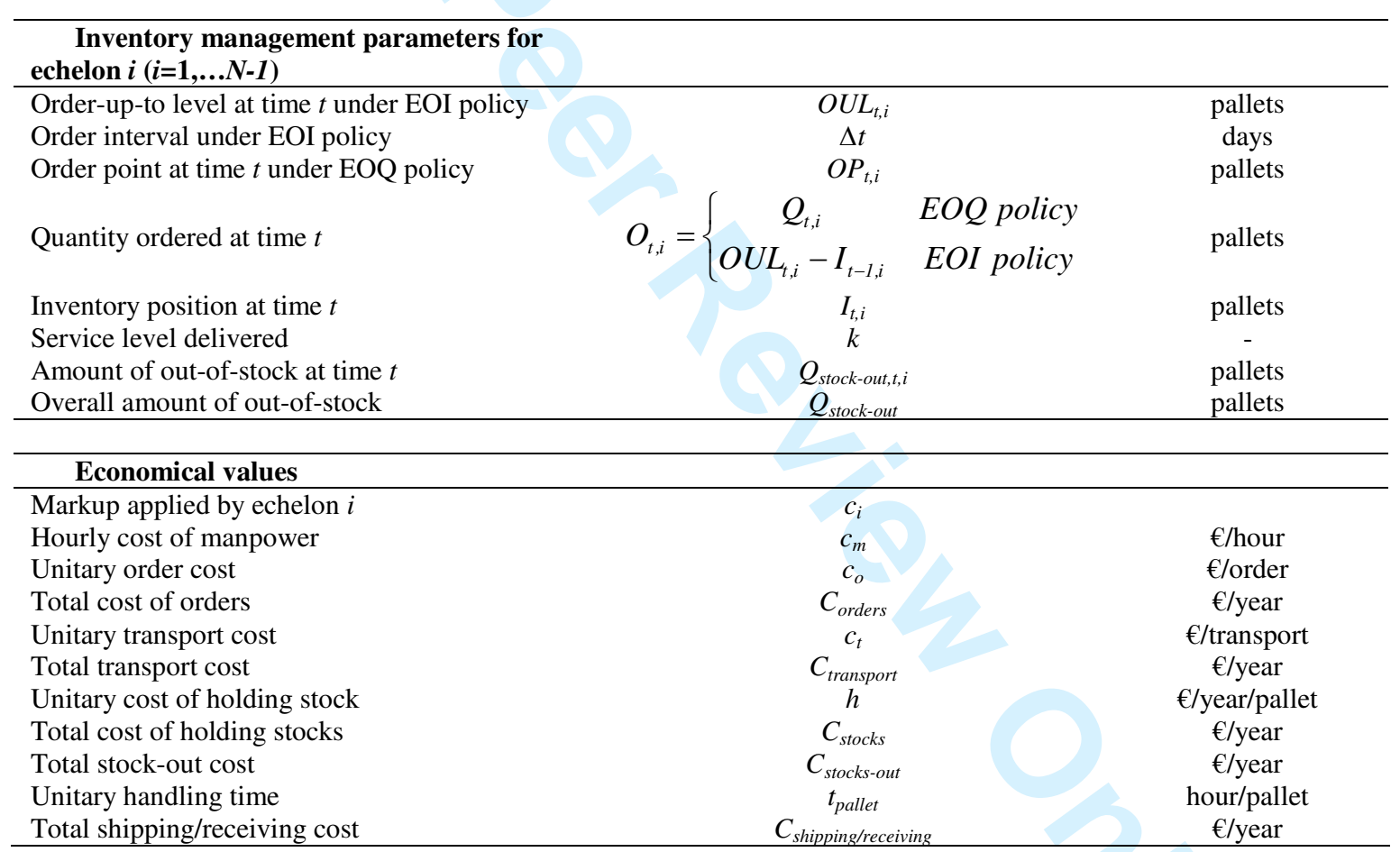


TABLE 2: bullwhip effect results for the scenario examined.

\begin{tabular}{lcc}
\hline & \multicolumn{2}{c}{ Bullwhip effect } \\
\cline { 2 - 3 } & $\sigma_{\text {orders }} \sigma$ & variance ratio \\
\hline EOI-5-no_sharing-no_peak & 108.4 & $11,750.59$ \\
EOI-5-no_sharing-peak-no_resp & 58.49 & $3,421.05$ \\
EOI-5-no_sharing-peak-resp & 53.24 & $2,834.20$ \\
EOI-4-no_sharing-no_peak & 36.53 & $1,334.12$ \\
EOI-4-no_sharing-peak-no_resp & 23.85 & 569.02 \\
EOI-4-no_sharing-peak-resp & 18.84 & 354.97 \\
EOQ-5-no_sharing-no_peak & 17.98 & 323.18 \\
EOI-3-no_sharing-no_peak & 14.77 & 218.14 \\
EOQ-4-no_sharing-no_peak & 14.25 & 202.92 \\
EOQ-3-no_sharing-no_peak & 11.24 & 126.24 \\
EOQ-5-no_sharing-peak & 10.11 & 102.15 \\
EOI-3-no_sharing-peak-no_resp & 9.73 & 94.62 \\
EOI-3-no_sharing-peak-resp & 8.91 & 79.42 \\
EOQ-4-no_sharing-peak & 8.34 & 69.59 \\
EOI-4-sharing-no_peak & 7.89 & 62.25 \\
EOI-3-sharing-no_peak & 7.88 & 62.12 \\
EOQ-3-sharing-no_peak & 7.7 & 59.36 \\
EOI-5-sharing-no_peak & 7.66 & 58.61 \\
EOQ-4-sharing-no_peak & 6.84 & 46.75 \\
EOQ-5-sharing-no_peak & 6.79 & 46.11 \\
EOQ-3-no_sharing-peak & 6.73 & 45.26 \\
EOQ-3-sharing-peak & 5.32 & 28.35 \\
EOQ-4-sharing-peak & 5.06 & 25.62 \\
EOQ-5-sharing-peak & 4.9 & 24.01 \\
EOI-4-sharing-peak-no_resp & 4.87 & 23.68 \\
EOI-3-sharing-peak-no_resp & 4.84 & 23.44 \\
EOI-3-sharing-peak-resp & 4.8 & 23.03 \\
EOI-4-sharing-peak-resp & 4.71 & 22.21 \\
EOI-5-sharing-peak-no_resp & 4.69 & 21.95 \\
EOI-5-sharing-peak-resp & 4.63 & 21.48 \\
\hline
\end{tabular}


TABLE 3: average total costs [€/year] for the scenarios examined.

\begin{tabular}{|c|c|c|c|c|c|c|}
\hline ID SCENARIO & TOTAL COSTS & Cost of holding stocks & Stock-out cost & Order cost & Transport cost & Shipping and receiving cost \\
\hline EOI-5-no_sharing-no_peak & $14,747,761.19$ & $12,695,583.38$ & $1,452,176.61$ & $1,358.40$ & $105,892.80$ & $492,750.00$ \\
\hline EOQ-5-no_sharing-peak & $6,533,270.95$ & $4,197,198.86$ & $1,471,176.48$ & $1,566.40$ & $122,179.20$ & $741,150.00$ \\
\hline EOQ-5-no_sharing-no_peak & $5,461,406.71$ & $3,790,859.18$ & $1,077,435.92$ & $1,270.40$ & $99,091.20$ & $492,750.00$ \\
\hline EOI-4-no_sharing-peak-no_resp & $5,186,724.78$ & $3,840,898.80$ & $659,421.49$ & $1,686.00$ & $128,856.00$ & $555,862.50$ \\
\hline EOQ-5-sharing-peak & $3,632,396.45$ & $767,442.36$ & $1,981,035.29$ & $1,807.20$ & $140,961.60$ & $741,150.00$ \\
\hline EOI-5-sharing-peak-resp & $3,587,797.15$ & $874,606.30$ & $1,706,329.25$ & $3,413.20$ & $262,298.40$ & $741,150.00$ \\
\hline EOI-4-no_sharing-no_peak & $3,398,587.89$ & $2,484,194.94$ & $443,136.45$ & $1,292.40$ & $100,401.60$ & $369,562.50$ \\
\hline EOQ-4-no_sharing-peak & $3,008,253.84$ & $1,733,412.66$ & $610,975.08$ & $1,393.20$ & $106,610.40$ & $555,862.50$ \\
\hline EOQ-5-sharing-no_peak & $2,934,056.21$ & $695,982.71$ & $1,636,145.50$ & $1,382.00$ & $107,796.00$ & $492,750.00$ \\
\hline EOI-4-sharing-peak-resp & $2,636,943.12$ & $611,658.51$ & $1,264,610.51$ & $2,635.60$ & $202,176.00$ & $555,862.50$ \\
\hline EOQ-4-sharing-no_peak & $2,441,693.77$ & $509,900.91$ & $1,479,902.76$ & $1,051.60$ & $81,276.00$ & $369,562.50$ \\
\hline EOQ-4-no_sharing-no_peak & $2,272,850.76$ & $1,437,082.13$ & $377,644.93$ & $1,138.80$ & $87,422.40$ & $369,562.50$ \\
\hline EOI-4-sharing-no_peak & $2,016,822.94$ & $598,189.29$ & $899,366.35$ & $1,910.40$ & $147,794.40$ & $369,562.50$ \\
\hline EOQ-3-sharing-peak & $1,944,395.81$ & $364,137.24$ & $1,131,895.17$ & $1,005.20$ & $76,783.20$ & $370,575.00$ \\
\hline EOI-3-sharing-peak-no_resp & $1,741,195.05$ & $363,546.30$ & $871,105.35$ & $1,777.20$ & $134,191.20$ & $370,575.00$ \\
\hline EOI-3-sharing-peak-resp & $1,728,346.57$ & $358,514.46$ & $861,191.91$ & $1,783.60$ & $136,281.60$ & $370,575.00$ \\
\hline EOQ-3-sharing-no_peak & $1,648,968.13$ & $314,576.02$ & $1,028,376.71$ & 766.00 & $58,874.40$ & $246,375.00$ \\
\hline EOI-3-no_sharing-peak-no_resp & $1,511,305.63$ & $707,635.68$ & $326,306.95$ & $1,394.40$ & $105,393.60$ & $370,575.00$ \\
\hline EOI-3-no_sharing-peak-resp & $1,493,487.98$ & $691,967.97$ & $321,107.41$ & $1,417.60$ & $108,420.00$ & $370,575.00$ \\
\hline EOQ-3-no_sharing-peak & $1,389,211.28$ & $709,975.41$ & $226,604.07$ & $1,061.60$ & $80,995.20$ & $370,575.00$ \\
\hline
\end{tabular}


TABLE 4: statistical analysis of experiments.

\begin{tabular}{|c|c|c|c|c|c|c|c|c|c|c|c|c|c|c|c|c|c|c|c|c|c|c|}
\hline & & \multicolumn{5}{|c|}{ Single effects } & \multicolumn{16}{|c|}{ Combined effects } \\
\hline \multirow{4}{*}{ 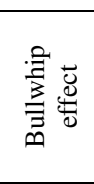 } & \multirow{4}{*}{$\begin{array}{l}3.89 \mathrm{E}+5 \\
9.98 \mathrm{E}+4 \\
3.84 \mathrm{E}+3\end{array}$} & & $\mathbf{A}$ & B & C & D & $\mathbf{A B}$ & $\mathbf{A C}$ & ABC & $\mathbf{A D}$ & ADE & BC & BD & CD & ABD & BCD & ACD & ABCD & ACDE & ABDE & BCDE & ABCDE \\
\hline & & $\overline{\text { SS }}$ & $3.69 \mathrm{E}+4$ & $2.97 \mathrm{E}+4$ & $4.51 \mathrm{E}+4$ & $2.84 \mathrm{E}+1$ & $.63 \mathrm{E}+4$ & $2.46 \mathrm{E}+4$ & $3.05 \mathrm{E}+4$ & $2.41 \mathrm{E}+4$ & $5.81 \mathrm{E}+2$ & $1.05 \mathrm{E}+4$ & $3.09 \mathrm{E}+4$ & $2 \mathrm{E}+$ & $1.47 \mathrm{E}+1$ & $3.90 \mathrm{E}+$ & $1.44 \mathrm{E}+1$ & $1.10 \mathrm{E}+2$ & $9.05 \mathrm{E}+0$ & $6.84 \mathrm{E}+3$ & $5.79 \mathrm{E}+3$ & $\overline{6.80 \mathrm{E}+3}$ \\
\hline & & MS & $3.69 \mathrm{E}+4$ & $2.97 \mathrm{E}+4$ & $4.51 \mathrm{E}+4$ & $2.84 \mathrm{E}+1$ & $63 \mathrm{E}+4$ & $2.46 \mathrm{E}+4$ & $.05 \mathrm{E}+4$ & $2.41 \mathrm{E}+4$ & $5.81 \mathrm{E}+2$ & $1.05 \mathrm{E}+4$ & $3.09 \mathrm{E}+4$ & $62 \mathrm{E}+$ & $1.47 \mathrm{E}+1$ & $3.90 \mathrm{E}+$ & $1.44 \mathrm{E}+1$ & $1.10 \mathrm{E}+2$ & $9.05 \mathrm{E}+0$ & $84 \mathrm{E}+3$ & $5.79 \mathrm{E}+3$ & $80 \mathrm{E}+3$ \\
\hline & & $\mathbf{F}$ & 9.61 & 7.73 & 11.76 & 0.01 & 9.46 & 6.40 & 7.95 & 6.29 & 0.15 & 2.73 & 8.04 & 0.00 & 0.00 & 0.00 & 0.00 & 0.03 & 0.00 & 1.78 & 1.51 & 1.77 \\
\hline \multirow{5}{*}{ 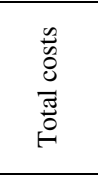 } & \multirow{5}{*}{$\begin{array}{r}\text { SSt } 1.82 \mathrm{E}+16 \\
\text { Sse } 2.60 \mathrm{E}+15 \\
\text { Mse } 1.00 \mathrm{E}+14\end{array}$} & & $\mathbf{A}$ & B & 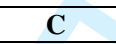 & D & & & & & & & & & & & & & & & BCDE & VE \\
\hline & & SS & $1.49 \mathrm{E}+15$ & $07 \mathrm{E}+15$ & $45 \mathrm{E}+15$ & $7.29 \mathrm{E}+14$ & -15 & $1.11 \mathrm{E}+15$ & $9.22 \mathrm{E}+14$ & $9 \mathrm{E}+14$ & $5.24 \mathrm{E}+14$ & $2.23 \mathrm{E}+14$ & $1.69 \mathrm{E}+15$ & $66 \mathrm{E}+14$ & +14 & $2.88 \mathrm{E}+14$ & $2.00 \mathrm{E}+14$ & $1.69 \mathrm{E}+14$ & $1.80 \mathrm{E}+14$ & $3.65 \mathrm{E}+13$ & $8.95 \mathrm{E}+13$ & $9 \mathrm{E}+13$ \\
\hline & & MS & $1.49 \mathrm{E}+15$ & $7 \mathrm{E}+15$ & $5 \mathrm{E}+15$ & $7.29 \mathrm{E}+14$ & $7 \mathrm{E}+15$ & $1 \mathrm{E}+15$ & $2 \mathrm{E}+14$ & $9 \mathrm{E}+14$ & $5.24 \mathrm{E}+14$ & $23 \mathrm{E}+14$ & $1.69 \mathrm{E}+15$ & $3.66 \mathrm{E}+14$ & $1.85 \mathrm{E}+14$ & $2.88 \mathrm{E}+14$ & $2.00 \mathrm{E}+14$ & $1.69 \mathrm{E}+14$ & $1.80 \mathrm{E}+14$ & $3.65 \mathrm{E}+13$ & $8.95 \mathrm{E}+13$ & $3.29 \mathrm{E}+13$ \\
\hline & & $\mathbf{F}$ & 14.856 & 30.627 & 4.479 & 7.282 & & & & & & 2.229 & & & & 2.882 & 1.995 & 1.687 & 1.794 & 0.365 & 0.894 & 0.329 \\
\hline & & sig & 0.001 & & & & & & & & & & & & & 0.102 & & & & & & 0.571 \\
\hline \multirow{5}{*}{ 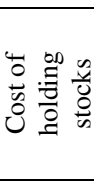 } & \multirow{5}{*}{$\begin{array}{l}\text { SSt } 1.38 \mathrm{E}+16 \\
\text { Sse } 2.19 \mathrm{E}+15 \\
\text { Mse } 8.42 \mathrm{E}+13\end{array}$} & & $\mathbf{A}$ & B & $\mathrm{C}$ & D & $\bar{B}$ & & $\mathrm{C}$ & AD & E & & & & & BCD & & & & & & CDE \\
\hline & & SS & $1.03 \mathrm{E}+15$ & $1.89 \mathrm{E}+15$ & $88 \mathrm{E}+15$ & $2.96 \mathrm{E}+14$ & $51 E+14$ & & $65 \mathrm{E}+14$ & 114 & $2.61 \mathrm{E}+14$ & $.59 \mathrm{E}+13$ & +15 & 14 & +14 & $2.03 \mathrm{E}+14$ & +14 & 1.99 & $1.79 \mathrm{E}+14$ & $8+13$ & $4.76 \mathrm{E}+13$ & $2.89 \mathrm{E}+13$ \\
\hline & & MS & $1.03 \mathrm{I}$ & 15 & & 2.961 & & & & & -14 & 13 & & & & $2.03 \mathrm{E}+14$ & & & $8+14$ & & +13 & $E+13$ \\
\hline & & $\mathbf{F}$ & 12. & 22 & & & & & 83 & & & & & & & 2.418 & & & 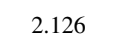 & & & .343 \\
\hline & & sig & & & & & & & & & & & & & & & & & & & & 63 \\
\hline \multirow{4}{*}{ 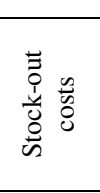 } & \multirow{4}{*}{$\begin{array}{c}\text { SSt } 4.04 \mathrm{E}+14 \\
\text { Sse } 8.88 \mathrm{E}+13 \\
\text { Mse } 3.42 \mathrm{E}+12\end{array}$} & & $\mathbf{A}$ & & & & & & & & & & & & & & & & & & & \\
\hline & & SS & 3 & & & & & & & & & & & & & +12 & & & & & & \\
\hline & & MS & $1.26 \mathrm{E}+13$ & $7.30 \mathrm{E}+13$ & & $3.27 \mathrm{E}+13$ & & 4.66 & $1.68 \mathrm{E}+12$ & $7.30 \mathrm{E}+11$ & $1.70 \mathrm{E}+13$ & $1.40 \mathrm{E}+13$ & $4.36 \mathrm{E}+12$ & & & 3.63E+12 & & $9.07 \mathrm{E}+11$ & $1.53 \mathrm{E}+10$ & & $3.17 \mathrm{E}+12$ & $1.67 \mathrm{E}+11$ \\
\hline & & sig & 0.066 & 0 & 55 & 0. & 0 & 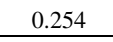 & 489 & 0.648 & 0.034 & 0.054 & 0.269 & 0.1 & 0.614 & 0.312 & 877 & 0.6 & 0.947 & 0.889 & 0.345 & 0.827 \\
\hline \multirow{5}{*}{ 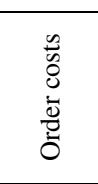 } & \multirow{5}{*}{$\begin{array}{cc}\text { SSt } & 7.60 \mathrm{E}+8 \\
\text { Sse } & 5.55 \mathrm{E}+7 \\
\text { Mse } & 2.14 \mathrm{E}+6\end{array}$} & & -1 & B & $\mathrm{c}$ & D & & & & & & & & & & & & & & & & \\
\hline & & $\overline{\text { SS }}$ & $39 \mathrm{E}+$ & 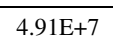 & $9 \mathrm{~F}_{-}$ & $\rho_{2}$ & $1.94 \mathrm{E}+8$ & $8.02 \mathrm{E}+6$ & $\mathrm{E}+7$ & $6.26 \mathrm{E}+6$ & +7 & $7 \mathrm{~F}+$ & +7 & $6.42 \mathrm{E}+6$ & $\mathrm{E}+6$ & $4.35 \mathrm{E}+6$ & $\mathrm{E}+6$ & $4.67 \mathrm{E}+6$ & $1.67 \mathrm{E}+6$ & $3 \mathrm{E}+6$ & $2.47 \mathrm{E}+6$ & $3.63 \mathrm{E}+5$ \\
\hline & & MS & 1.39 & 7 & & & & & & & & 4.3 & & & & $4.35 \mathrm{E}+6$ & & & & & & $3 \mathrm{E}+5$ \\
\hline & & $\mathbf{F}$ & 64 & & & & & & & & & & & & & 2.038 & & & & & & 70 \\
\hline & & sig & 0.0 & & & & & & & & & 0. & & & & 0.165 & & 0 & & 0.4 & 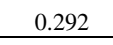 & 0.684 \\
\hline \multirow{5}{*}{ 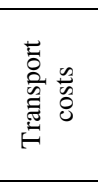 } & \multirow{5}{*}{$\begin{array}{l}\text { SSt } 4.47 \mathrm{E}+12 \\
\text { Sse } 3.46 \mathrm{E}+11 \\
\text { Mse } 1.33 \mathrm{E}+10\end{array}$} & & E. & - & C & & & & & & & & & & & BCD & & & & & & ABCDE \\
\hline & & SS & $01 \mathrm{E}-$ & (2) & $9 \mathrm{E}+11$ & (2) & & & $8+11$ & & & $68 \mathrm{E}+11$ & & $82 \mathrm{E}+10$ & & $2.49 \mathrm{E}+10$ & & & & & & $24 \mathrm{E}+9$ \\
\hline & & MS & $8.01 \mathrm{E}+11$ & $2 \mathrm{E}+11$ & & $6.29 \mathrm{E}+11$ & & +10 & +11 & & +11 & $E+11$ & & & & $2.49 \mathrm{E}+10$ & & & & & +10 & $4 \mathrm{E}+9$ \\
\hline & & $\mathbf{F}$ & 60.205 & 22.696 & 10.448 & 47.2 & & 3. & 8.718 & & 30 & & 4. & 2.8 & 2.4 & 1.873 & 0. & 1.986 & 0.709 & 0.704 & 1.210 & 0.168 \\
\hline & & sig & 0.000 & 0.000 & 0.003 & 0.000 & 0.000 & 0.074 & 0.007 & 0.110 & 0.000 & 0.000 & 0.036 & 0.102 & 0.127 & 0.183 & 0.334 & 0.171 & 0.407 & 0.409 & 0.281 & 0.685 \\
\hline \multirow{5}{*}{ 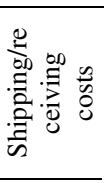 } & \multirow{5}{*}{$\begin{array}{c}\text { SSt } 6.09 \mathrm{E}+13 \\
\text { Sse } 5.69 \mathrm{E}+12 \\
\text { Mse } 2.19 \mathrm{E}+11\end{array}$} & & $\bar{A}$ & & C & & & & & & & & & & & BCD & & & & & & CDE \\
\hline & & $\overline{\text { SS }}$ & $3.09 \mathrm{E}+12$ & ( & 0 & & & & $8+10$ & & & & & & & & & & & & & \\
\hline & & MS & $3.09 \mathrm{E}+12$ & $9.26 \mathrm{E}+12$ & $4.29 \mathrm{E}+10$ & $9.46 \mathrm{E}+12$ & $2.29 \mathrm{E}+13$ & $7.43 \mathrm{E}+11$ & $4.29 \mathrm{E}+10$ & $4.29 \mathrm{E}+10$ & $3.09 \mathrm{E}+12$ & $3.09 \mathrm{E}+12$ & $4.29 \mathrm{E}+10$ & $1.69 \mathrm{E}+12$ & $4.29 \mathrm{E}+10$ & $7.43 \mathrm{E}+11$ & $4.29 \mathrm{E}+10$ & $4.29 \mathrm{E}+10$ & $4.29 \mathrm{E}+10$ & $4.29 \mathrm{E}+10$ & $7.43 \mathrm{E}+11$ & $4.29 \mathrm{E}+10$ \\
\hline & & $\mathbf{F}$ & 14.119 & 42.304 & 0.196 & 43.201 & 104.599 & 3.395 & 0.196 & 0.196 & 14.119 & 14.119 & 0.196 & 7.734 & 0.196 & 3.395 & 0.196 & 0.196 & 0.196 & 0.196 & 3.395 & 0.196 \\
\hline & & sig & 0.001 & 0.000 & 0.662 & 0.000 & 0.000 & 0.077 & 0.662 & 0.662 & 0.001 & 0.001 & 0.662 & 0.010 & 0.662 & 0.077 & 0.662 & 0.662 & 0.662 & 0.662 & 0.077 & 0.662 \\
\hline
\end{tabular}


TABLE 5: percentage values of total costs and bullwhip effect (used for FIGURE 7\%FIGURE 10).

\begin{tabular}{lcc}
\hline & $\begin{array}{c}\text { Bullwhip effect } \\
\text { (percentage values) }\end{array}$ & $\begin{array}{c}\text { Total cost } \\
\text { (percentage values) }\end{array}$ \\
\hline EOQ-5-sharing-peak & $4.52 \%$ & $18.19 \%$ \\
EOQ-5-sharing-no_peak & $6.26 \%$ & $14.69 \%$ \\
EOQ-5-no_sharing-peak & $9.33 \%$ & $32.71 \%$ \\
EOQ-5-no_sharing-no_peak & $16.59 \%$ & $27.34 \%$ \\
EOQ-4-sharing-peak & $4.67 \%$ & $14.26 \%$ \\
EOQ-4-sharing-no_peak & $6.31 \%$ & $12.22 \%$ \\
EOQ-4-no_sharing-peak & $7.69 \%$ & $15.06 \%$ \\
EOQ-4-no_sharing-no_peak & $13.15 \%$ & $11.38 \%$ \\
EOQ-3-sharing-peak & $4.91 \%$ & $9.73 \%$ \\
EOQ-3-sharing-no_peak & $7.10 \%$ & $8.26 \%$ \\
EOQ-3-no_sharing-peak & $6.21 \%$ & $6.96 \%$ \\
EOQ-3-no_sharing-no_peak & $10.37 \%$ & $5.68 \%$ \\
'EOI-5-sharing-peak-resp & $4.27 \%$ & $17.96 \%$ \\
EOI-5-sharing-peak-no_resp & $4.33 \%$ & $18.21 \%$ \\
EOI-5-sharing-no_peak & $7.07 \%$ & $13.59 \%$ \\
EOI-5-no_sharing-peak-resp & $49.11 \%$ & $73.06 \%$ \\
EOI-5-no_sharing-peak-no_resp & $53.96 \%$ & $100.00 \%$ \\
EOI-5-no_sharing-no_peak & $100.00 \%$ & $73.84 \%$ \\
EOI-4-sharing-peak-resp & $4.35 \%$ & $13.20 \%$ \\
EOI-4-sharing-peak-no_resp & $4.49 \%$ & $13.21 \%$ \\
EOI-4-sharing-no_peak & $7.28 \%$ & $10.10 \%$ \\
EOI-4-no_sharing-peak-resp & $17.38 \%$ & $18.98 \%$ \\
EOI-4-no_sharing-peak-no_resp & $22.00 \%$ & $25.97 \%$ \\
EOI-4-no_sharing-no_peak & $33.70 \%$ & $17.02 \%$ \\
EOI-3-sharing-peak-resp & $4.43 \%$ & $8.65 \%$ \\
EOI-3-sharing-peak-no_resp & $4.46 \%$ & $8.72 \%$ \\
EOI-3-sharing-no_peak & $7.27 \%$ & $6.95 \%$ \\
EOI-3-no_sharing-peak-resp & $8.22 \%$ & $7.97 \%$ \\
EOI-3-no_sharing-peak-no_resp & $8.98 \%$ & \\
EOI-3-no_sharing-no_peak & $13.63 \%$ & \\
\hline
\end{tabular}

